University of Wollongong

Research Online

Faculty of Engineering and Information

Faculty of Engineering and Information

Sciences - Papers: Part B

Sciences

2019

Development and evaluation of a comfort-oriented control strategy for thermal management of mixed-mode ventilated buildings

Massimo Fiorentini

University of Wollongong, massimo@uow.edu.au

Gianluca Serale

Politecnico di Torino, gianluca.serale@polito.it

Georgios Kokogiannakis

University of Wollongong, gkg@uow.edu.au

Alfonso Capozzoli

Politecnico di Torino, alfonso.capozzoli@polito.it

Paul Cooper

University of Wollongong, pcooper@uow.edu.au

Follow this and additional works at: https://ro.uow.edu.au/eispapers1

Part of the Engineering Commons, and the Science and Technology Studies Commons

Research Online is the open access institutional repository for the University of Wollongong. For further information contact the UOW Library: research-pubs@uow.edu.au 


\title{
Development and evaluation of a comfort-oriented control strategy for thermal management of mixed-mode ventilated buildings
}

\author{
Abstract \\ The paper presents the development, implementation and performance investigation via simulations and \\ experiments of a comfort-oriented control strategy for natural ventilation and mechanical air conditioning \\ management of a mixed-mode building. The proposed comfort-oriented control strategy determines \\ whether it would be possible to operate in natural ventilation mode or in mechanical heating/cooling. The \\ control algorithm calculates first the optimal opening percentage of the windows according to adaptive \\ thermal comfort criteria. If natural ventilation cannot guarantee the thermal comfort requirements and \\ mechanical conditioning is required, the algorithm dynamically optimises the heating or cooling set-point \\ targeting a defined Predicted Mean Vote (PMV) index objective. The performance of the proposed \\ controller was tested via simulations and experiments by using a residential mixed-mode building as a \\ case study. The house features operable windows, a reverse-cycle ducted air conditioner and a \\ comprehensive experimental control and monitoring infrastructure. A comparison with a baseline control \\ strategy was performed to evaluate the comfort and energy performance improvement potential of the \\ proposed control algorithm. The comfort-oriented controller was proven to outperform the baseline \\ controller in terms of maintaining comfort in accordance with targets set by the current comfort \\ standards, such as deviation from a PMV set-point or the middle of the adaptive thermal comfort band. \\ The building energy consumption was also reduced in cooling dominated conditions. The experimental \\ tests demonstrated that this logic can be integrated in an embedded controller, and its performance is in \\ line with the expected one from the simulation results.

\section{Disciplines} \\ Engineering | Science and Technology Studies

\section{Publication Details} \\ Fiorentini, M., Serale, G., Kokogiannakis, G., Capozzoli, A. \& Cooper, P. (2019). Development and evaluation \\ of a comfort-oriented control strategy for thermal management of mixed-mode ventilated buildings. \\ Energy and Buildings, 202 109347-1-109347-16.
}




\section{Development and evaluation of a comfort-oriented control strategy for thermal management of mixed-mode ventilated buildings}

Massimo Fiorentini*a , Gianluca Serale ${ }^{\mathrm{b}, \mathrm{c}}$, Georgios Kokogiannakis ${ }^{\mathrm{a}}$, Alfonso Capozzoli ${ }^{\mathrm{b}}$, Paul Cooper ${ }^{\mathrm{a}}$

a Sustainable Buildings Research Centre (SBRC), Faculty of Engineering and Information Sciences, University of Wollongong, New South Wales, 2522, Australia

${ }^{\mathrm{b}}$ Department of Energy (DENERG), TEBE Research group, Politecnico di Torino, Corso Duca degli Abruzzi, 24, 10129 Turin, Italy

c CHAOS Lab, Andlinger Center for Energy and Environment, Princeton University, Princeton, NJ, 08544, USA

Declarations of interest: none

*Corresponding Author: massimo@uow.edu.au

Abstract: The paper presents the development, implementation and performance investigation via simulations and experiments of a comfort-oriented control strategy for natural ventilation and mechanical air conditioning management of a mixed-mode building. The proposed comfort-oriented control strategy determines whether it would be possible to operate in natural ventilation mode or in mechanical heating/cooling. The control algorithm calculates first the optimal opening percentage of the windows according to adaptive thermal comfort criteria. If natural ventilation cannot guarantee the thermal comfort requirements and mechanical conditioning is required, the algorithm dynamically optimises the heating or cooling set-point 
24 targeting a defined Predicted Mean Vote index objective. The performance of the proposed 25 controller was tested via simulations and experiments by using a residential mixed-mode 26 building as a case study. The house features operable windows, a reverse-cycle ducted air 27 conditioner and a comprehensive experimental control and monitoring infrastructure. A 28 comparison with a baseline control strategy was performed to evaluate the comfort and energy 29 performance improvement potential of the proposed control algorithm. The comfort-oriented controller was proven to outperform the baseline controller in terms of maintaining comfort in

31 accordance with targets set by the current comfort standards, such as deviation from a PMV 32 set-point or the middle of the adaptive thermal comfort band. The building energy consumption 33 was also reduced in cooling dominated conditions. The experimental tests demonstrated that 34 this logic can be integrated in an embedded controller, and its performance is in line with the expected one from the simulation results.

37 Keywords: Adaptive thermal comfort; Mixed mode ventilation; Natural ventilation and HVAC control; PMV-based control; Building management systems; 
$41 \quad I_{c l}=$ clothing level index [clo]

$42 w p=$ operable windows' opening percentage level (control action) [\%]

$43 \quad k=$ control time step index

$44 \quad M=$ metabolic rate index [met]

45 mode $=$ operating mode

$46 \beta=$ room volume air changes per control time-step

$47 \quad \varepsilon_{T o}=$ cumulative error from temperature set-point in natural ventilation

$48 \quad \varepsilon_{P M V}=$ cumulative error from PMV set-point in mechanical ventilation

$49 P M V_{i}=$ indoor Predicted Mean Vote (PMV) index

$50 P M V_{\text {set, }}=$ target $\mathrm{PMV}$ in cooling mode

$51 P M V_{\text {set }, h}=$ target $\mathrm{PMV}$ in heating mode

$52 R H_{i}=$ indoor relative humidity [\%]

$53 T_{m, j}=$ calculated mixed indoor air temperature $\left[{ }^{\circ} \mathrm{C}\right]$

$54 T_{a}=$ indoor air temperature $\left[{ }^{\circ} \mathrm{C}\right]$

$55 T_{\text {out }}=$ outdoor air temperature $\left[{ }^{\circ} \mathrm{C}\right]$

$56 T_{o}=$ operative temperature $\left[{ }^{\circ} \mathrm{C}\right]$

$57 T_{g i}=$ indoor black globe temperature $\left[{ }^{\circ} \mathrm{C}\right]$

$58 \overline{T_{r}}=$ calculated indoor mean radiant temperature $\left[{ }^{\circ} \mathrm{C}\right]$

$59 \quad T_{r m}=$ running mean temperature $\left[{ }^{\circ} \mathrm{C}\right]$

$60 T_{A C \text {,set }}=$ target air conditioner temperature set-point $\left[{ }^{\circ} \mathrm{C}\right]$ 
$61 T_{N V \text {,set }}=$ target natural ventilation temperature set-point $\left[{ }^{\circ} \mathrm{C}\right]$

62

$\theta=$ wind direction $\left[{ }^{\circ}\right]$

$63 \quad v_{a r}=$ indoor relative air velocity $[\mathrm{m} / \mathrm{s}]$

64

$v_{w}=$ wind velocity $[\mathrm{m} / \mathrm{s}]$

\section{Introduction and background}

66 Heating and cooling to maintain appropriate thermo-hygrometric conditions in buildings is a substantial energy end use [1]. Many studies have explored opportunities to reduce energy consumption for heating and cooling through improvements to the building fabric, more efficient HVAC equipment, or implementation of intelligent energy management systems [2,3]. Increasing affordability of electronic componentry has led to an expansion in the deployment of distributed sensors and controllers in buildings. Combined with improved computational power in embedded controllers, this has created an opportunity for more advanced control strategies for the optimisation of energy and comfort in buildings. The management of these increasingly complex strategies, which may utilise various resources to optimise for multiple control objectives, is an important challenge.

There is a substantial body of literature exploring innovative control logics with a focus on commercial, institutional or educational buildings. However, fewer studies have focussed on the use of innovative controls in residential buildings. Building Energy Management Systems (BEMS) are typically only implemented in non-residential buildings [4]. This is primarily for economic reasons, as the initial investment for non-residential buildings is generally much higher than for residential, and it is easier to justify the substantial capital cost of a BEMS.

82 BEMS allow a significant number of variables to be monitored and for the HVAC parameters to be dynamically modified [5]. Newer technologies, such as 'smart thermostats', are becoming 
more common in residential applications. However, these systems are simpler than traditional BEMS, and are only applicable in certain situations. A promising energy management strategy is the automatic windows opening which plays a fundamental role in maintaining suitable indoor comfort conditions in residential buildings [6, 7], but is not typically incorporated into simple control solutions.

\subsection{Control of mixed-mode buildings}

In mixed mode residential buildings with automated window opening, the mechanical heating and cooling system should be integrated with the window opening controller. The basic concept for these buildings is to maintain a satisfactory indoor environment by alternating between and combining natural and mechanical systems to reduce the use of the HVAC system throughout the year [8]. Depending on the location, natural ventilation can substantially reduce energy consumption in a building $[9,10]$, and the control of natural ventilation operation plays an important role in achieving this reduction, either by being manually operated and reliant on human behaviour [11] or automated with simple or complex control algorithms [12,13].

Natural ventilation has additional benefits in certain circumstances, including improved indoor air quality (when the building is located in a non-polluted area) and a reduced risk of overheating in summer [14].

101 Although many climatic zones are suitable for the utilisation of natural ventilation in buildings,

102 in particular in Australia [15] the literature reports relatively few cases of buildings that fully

103 exploit an optimised natural ventilation strategy. This is often due to the lack of an optimised automated control system for the windows openings, and the inability of the occupants to open and close the windows in the right conditions to exploit the natural ventilation potential [16]. opening percentage in order to manage air velocity in the space. Air velocity can strongly affect 
an occupants' perceived comfort and cause local discomfort due to draughts [17]. Raja et al.

109 [18] highlighted the direct positive relationship between an occupants' willingness to interact

110 with the natural ventilation control of their office space, and their thermal comfort. Providing

111 occupants with manual control over window opening, or relying on predefined opening

112 schedules has been shown to lead to an increased risk of thermal discomfort, and to energy

113 wastage, which can negate the energy savings achievable from natural ventilation $[19,20]$.

114 In cases where a control system is in place for the operation of windows, the integration and coordination of the operable windows with the conventional HVAC system is challenging

$116[21,22]$.

117 Assessing the best logic for mixed-mode buildings is non-trivial, since factors influencing

118 comfort in natural and mechanical ventilation have to be considered simultaneously, as well as

119 the response of the building to various forcing variables (outdoor temperature, humidity, wind speed and direction). Mixed-mode buildings typically feature a high-level controller that defines whether the building can operate in natural ventilation or must rely on mechanical air conditioning based on a set of predefined rules. A lower level controller will then either determine the window opening percentage or activate the mechanical system. The indoor temperature set-point for the mechanical systems is then generally fixed and pre-defined, and the heating or cooling control algorithms work independently from the window opening controller logic.

127 The assessment of occupants' thermal comfort in mixed-mode buildings is also a challenging task [23-25]. Rijal et al., [19] found that thermal conditions in mixed-mode buildings were generally controlled as if they were in naturally ventilated buildings, but with the provision for cooling if needed, rather than as in normal air-conditioned buildings. The well-known Predicted Mean Vote (PMV) can only be used to evaluate the microclimatic conditions of conditioned environments, while the adaptive thermal comfort theory is only applicable to 
133 passive naturally ventilated buildings. Traditional thermostatic controllers regulate the active

134 system of the building based on indoor dry-bulb temperature measurements. Controlling

135 internal temperature based on adaptive thermal comfort theory requires measurement of a 136 greater number of parameters, for instance Mean Radiant Temperature [26] or feedback from 137 the occupants [27], in order to compute comfort indexes in real time and thereby optimise the 138 building operation.

\subsection{Recent advances in control algorithms for mixed-mode buildings}

140 There are several examples of recent research focused on control strategies for mixed mode

141 ventilation buildings. Drake et al., [8] assessed the thermal sensations of occupants of two 142 mixed-mode office buildings, i.e., one educational and one commercial. The control logic 143 implemented operated a fixed set-point for the air conditioning system $\left(24^{\circ} \mathrm{C}\right)$ with a large 144 deadband $\left( \pm 1.5^{\circ} \mathrm{C}\right)$. The controllers switched-over to natural ventilation mode only when 145 external weather conditions or indoor thermal temperatures met pre-defined conditions (e.g., 146 outdoor air temperature below a specific threshold). Fu and $\mathrm{Wu}$ [28] stated that occupant 147 comfort must be the primary objective of a controller in hybrid ventilated buildings. Psomas et 148 al. [14] conducted a simulation study on the automated control of a single-family house with 149 operable openings. The study defined a methodology and a framework of how to simulate a 150 ventilative cooling algorithm of a window system in a building simulation performance tool.

151 Several studies have identified an approach using Model Predictive Control (MPC) more suitable to capture the complex dynamics of mixed-mode buildings. May-Ostendorp et al. [29] and Zhao et al. [30] formulated a Model Predictive Control problem in Matlab for regulating mixed-mode buildings, represented by simulations in EnergyPlus. $\mathrm{Hu}$ and Karava [31,32] conducted a simulation study based on model-based controller formulation. They found that the non-linearities introduced by the natural ventilation airflow network required the adoption 
157 of a numerical optimization, i.e., a Particle Swarm Optimisation algorithm, which has

158 implications for the computational performance of an embedded controller. Spindler and

159 Norford $[33,34]$ presented different configurations of a short term predictive controller acting

160 as a supervisory control layer for optimising the internal air temperature set-point of a mixed-

161 mode ventilated institutional building. The optimal solution was provided by a model-based

162 controller, using both building and airflow network models tailored with data gathered in field.

163 The control input influenced only the flow rate of outdoor air entering in the building using

164 automated openings or mechanical fans, with the regulation of the active HVAC system

165 identified as an area for further research. In 2018, Chen et al. [35] further demonstrated the

166 effectiveness of MPC algorithms for the regulation of hybrid ventilated buildings. This study

167 was based on numerical simulations implementing a non-linear MPC using an artificial neural

168 network to model the dynamic behaviour of a building. These studies have all demonstrated

169 the potential effectiveness of MPC regulation for building performance. Challenges remain in

170 the detailed definition of a control oriented model for the implementation of MPC in real

171 buildings, as well as in creating a controller that can be employed in a large number of

172 buildings.

173 Barbadilla-Martín et al. [36] used an adaptive comfort algorithm to recursively adjust the

174 indoor air temperature set-point (and the controller deadband) of 11 mixed-mode office spaces

175 in Spain. A large dataset was analysed in this paper, which outlined the complications inherent

176 in defining a suitable baseline for calculating the energy savings achievable by means of

177 experimental tests with different controllers. A limitation in this study was that although the

178 windows were manually operated, this study considered the investigated offices as a mixed-

179 mode building by limiting the control logic to the definition of the mechanical HVAC system 180 set-point. 
182 A number of strategies have been employed in previous literature for the management of 183 mixed-mode buildings, without a clear consensus on the optimal method. Practitioners 184 therefore typically use a tailored approach in devising regulation strategies for mixed-mode 185 buildings, as a result of the lack of standard methods. Standards still conservatively categorize 186 mixed-mode buildings as part of fully mechanically conditioned environments. This constrains

187 mixed-mode buildings to operate in a restrictive PMV range, and therefore a comfort-based control algorithm for the regulation of the indoor conditions is not able to maximize the energy saving. Many authors have addressed this lack in the regulation of the conditions in mixedmode buildings by providing long-term comfort assessments [37,38], comparing in-situ

191 measurements and questionnaires to thermal comfort standards [39] and analysing the 192 occupants' response to conditions occurred during the mechanical and natural ventilation operating modes of the building [40]. Luo et al. [41] explored this issue, and found that adaptive comfort theories better predict the thermal sensation of mixed-mode buildings occupants, compared with the steady state PMV model. A guideline for integrating adaptive thermal comfort requirements within traditional PMV theory can be found in the standard ISSO 74

197 (ATG) of Netherlands [42].

\subsection{Goals and framework of the paper}

199 The current paper presents a comfort-oriented control strategy, which aims at maximising 200 indoor thermal comfort by adapting the controller objective to the relevant thermal comfort 201 theory for the chosen ventilation mode. The adaptive thermal comfort theory was employed to 202 optimise the operation of the natural ventilation mode operation, while the PMV index was 203 used for periods of mechanical heating and cooling operation. The ASHRAE Standard 55 was 204 considered as the reference for the calculation of the control targets [43]. 
205 The controller was developed using affordable electronic devices to demonstrate that this 206 solution could be scalable at residential level. In order to reduce the energy demand, natural

207 ventilation through opening of the windows was selected as the preferred building operating 208 mode. When the building operated in this mode, a simplified air flow network was solved to 209 predict the air temperature at the next control time step, and to determine to optimal window 210 opening percentage for thermal comfort. If opening the windows was not able to guarantee the 211 satisfaction of the adaptive thermal comfort bounds, mechanical heating or cooling was 212 activated. In this scenario, the controller optimised the set-point of the air conditioning system 213 by calculating the temperature at which the desired PMV level would be achieved.

214 The controller's performance was tested using numerical simulations and experimental tests.

215 A case study residential building was used for both the simulations and the experimental tests.

216 A dedicated simulation platform that linked building energy performance simulation software 217 and an external controller at each time-step was developed for this purpose. This was used to 218 benchmark the performance of the comfort-oriented control strategy against a baseline 219 controller under the same operating conditions.

220 The same control algorithms were also implemented in a low-cost controlling hardware, and 221 integrated into the control system of the case study house. This provided a practical 222 demonstration of the integration of the logic in an embedded controller, as well as providing experimental validation of the simulation results through comparison of the performance of the 224 comfort-oriented control strategy against a baseline controller. 


\section{Methodology}

\subsection{Baseline controller}

228

The adaptive controller developed in this study was compared with a baseline competing algorithm. The baseline algorithm was the controller originally implemented in the case study building that was employed in the current study (see Section 3). The implementation of the baseline controller was based on rules sourced from building operation specifications defined by a building mechanical engineering consultant.

The baseline controller switched between natural and mechanical ventilation, and determined the window opening percentage, based on the measurement of the outdoor dry-bulb temperature $T_{\text {out }}$ as follows:

- When the outdoor temperature was between $20^{\circ} \mathrm{C}-24^{\circ} \mathrm{C}$, the windows were fully open;

- If the outdoor temperature was between $18^{\circ} \mathrm{C}-20^{\circ} \mathrm{C}$ and $24^{\circ} \mathrm{C}-26^{\circ} \mathrm{C}$ windows were open at $50 \%$, only if heating or cooling mode are not already active. These partial openings do not allow the full benefits of natural ventilation to be exploited. For instance, night cooling can be effectively used in the summer time by completely opening the windows when the outdoor temperature reaches values within the $24-26$ ${ }^{\circ} \mathrm{C}$ band.

- When the outdoor temperature was below $18^{\circ} \mathrm{C}$ the heating mode was activated and the air conditioner was configured with a constant indoor temperature set-point of $20^{\circ} \mathrm{C}$. The heating mode was then deactivated when the outdoor temperature reached $20^{\circ} \mathrm{C}$. The cooling mode was activated when the outdoor temperature exceeded $26^{\circ} \mathrm{C}$ and deactivated at $24^{\circ} \mathrm{C}$, with an indoor temperature set-point of $24^{\circ} \mathrm{C}$. 


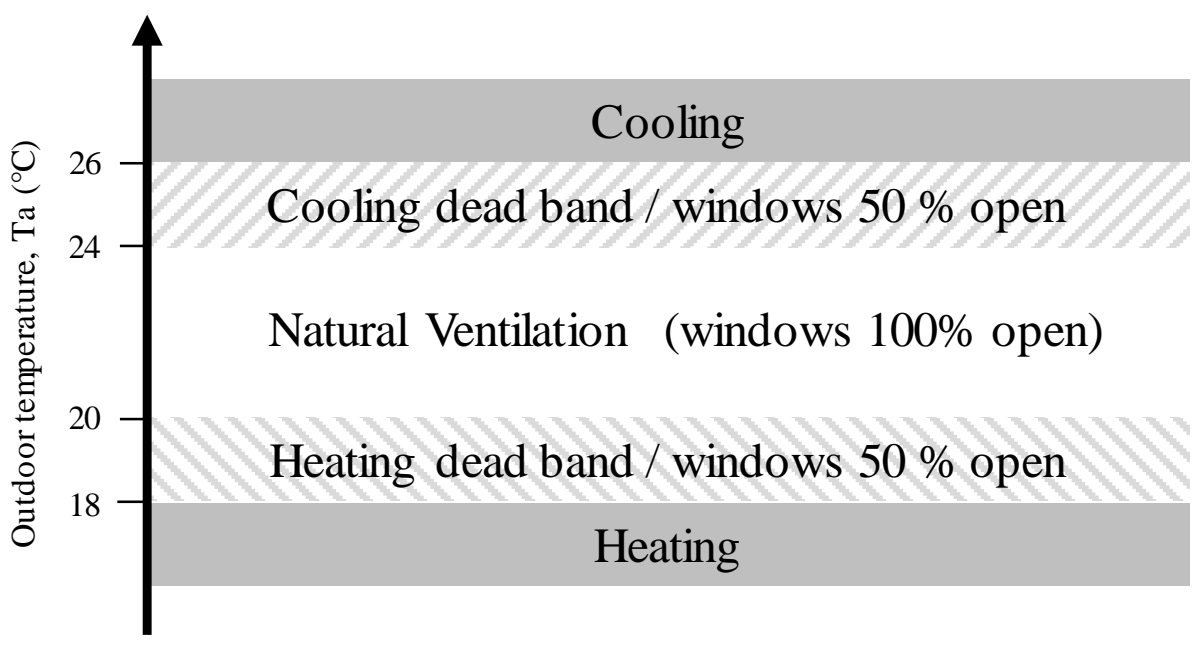

Figure 1: Baseline controller operating mode decision logic.

\subsection{Formulation of the comfort-oriented control strategy}

Multiple factors beyond dry bulb temperature affect perception of thermal comfort, therefore a simple thermostat based control will not always be sufficient to capture the required information to maintain comfort in a mixed-mode building. The goal of the proposed comfortbased controller algorithm for window openings was to improve the occupants' comfort satisfaction in accordance with the limits and comfort indexes used in current thermal comfort standards [43].

The proposed comfort-oriented control strategy would generally be active only when the house is occupied, because windows will typically be shut when the building is unoccupied due to security concerns (precluding natural ventilation), and mechanical conditioning will not typically be active for energy saving purposes. Occupancy detection could be implemented in the controller by using presence/motion sensors or manual user inputs. However, since this study includes experimental tests that are affected by a number of unmeasured disturbances, we decided to remove the additional uncertainty resulting from unknown occupant behaviour.

266 The experimental campaign was therefore undertaken with the house unoccupied to achieve 
equivalent and comparable results.

268 The control of the mixed-mode ventilation was achieved in two steps. Firstly, the operating mode for the current control time-step was determined (either natural ventilation or mechanical conditioning). Secondly, either the optimal set-point of window opening percentage or the air

271 conditioner temperature set-point was defined, depending on the operating mode that was set

272 from the first step. The controller aimed to predict the outcome of all the possible subsequent

273 control actions and then select the optimal solution.

274 Current comfort standards are either applicable to fully naturally ventilated (e.g. adaptive thermal comfort) or to fully mechanically ventilated buildings (e.g. PMV method), since there is no defined standard that is applicable to a mixed-mode building. The absence of defined standards applicable to mixed mode buildings is reflected in the proposed controller logic, as it integrates two different comfort theories for managing a mixed-mode building. During the controller development, the principles of the adaptive comfort theory were used to determine if the building could use natural ventilation, as well as the set-point temperature that had to be maintained through the opening of windows. If natural ventilation could maintain the indoor conditions within the prescribed constraint, it was always preferred since it exploits the climatic potential and reduces the building energy consumption. The controller logic allows operable windows to be operated at steps of opening of $20 \%$ (this percentage could be reconfigured depending on the window type). When natural ventilation was not possible and mechanical heating or cooling was required, the PMV index was adopted as an objective for the controller to indicate occupant comfort. PMV is currently the most recognized thermal comfort indicator for fully mechanically ventilated buildings. A schematic of the control process is presented in Figure 2. 


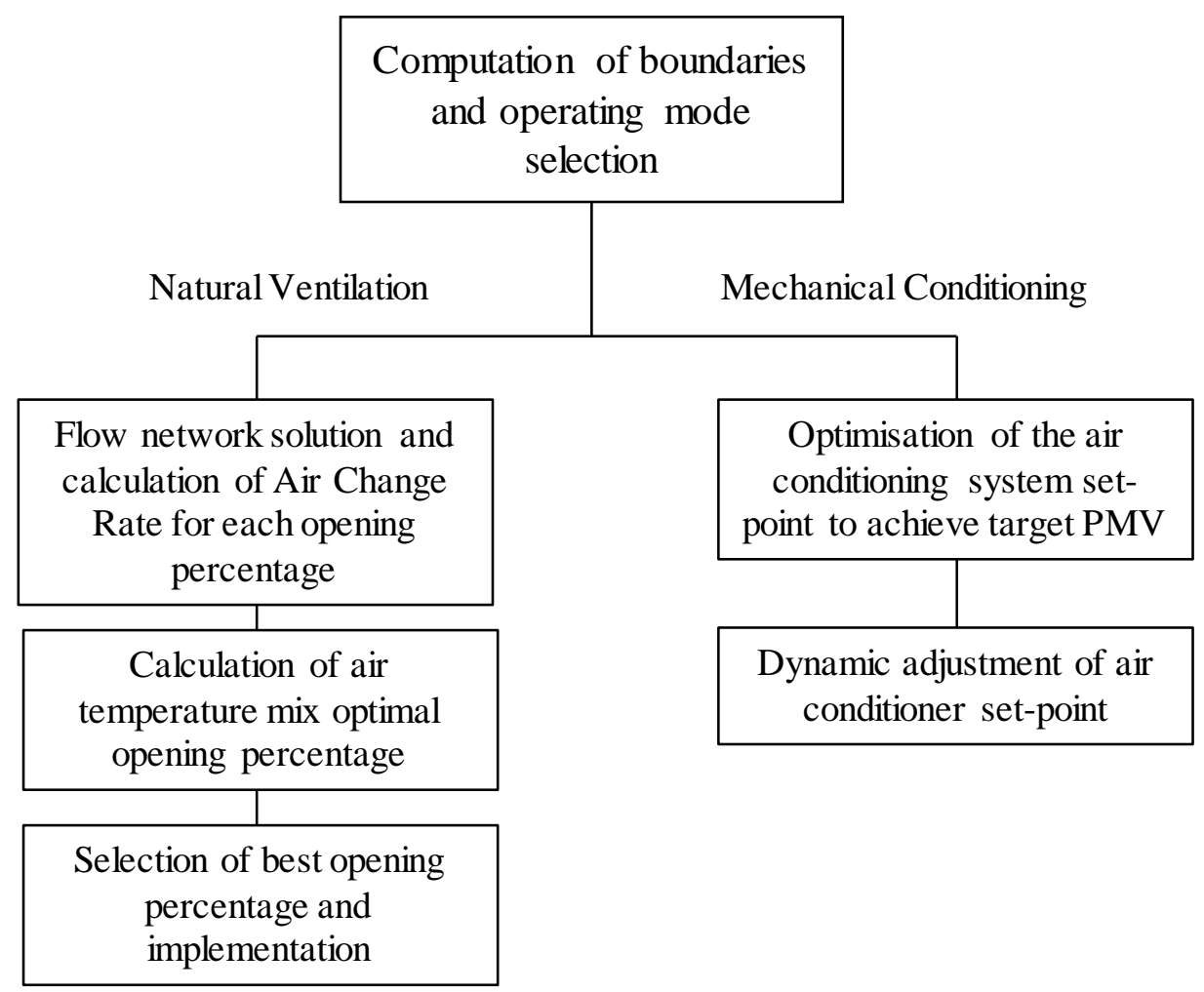

Figure 2: Process schematic for comfort-oriented control.

292 The set-points and boundaries used in the proposed controller logic are not fixed thresholds

293 before the deployment of the controller, but they are daily re-calculated values capable of 294 considering the variation of an occupant's acceptability bands of adaptive thermal comfort.

295 Figure 3 shows the variation of the set-point and the relative bounds for seven days of 296 operations. 


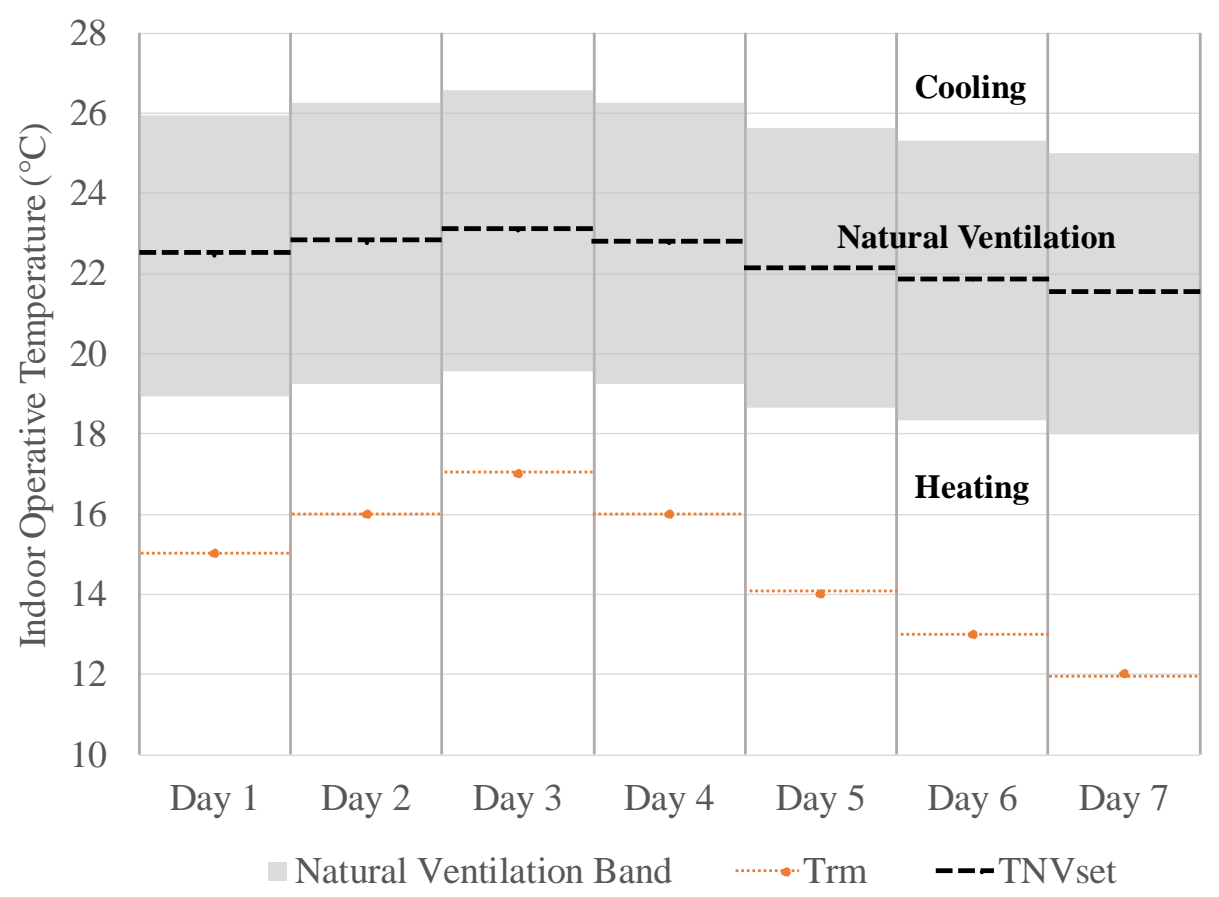

Figure 3: An example illustrating the evolution of the comfort-oriented controller set-points over time. The grey area represents the periods during which the controller will select the natural ventilation mode.

\subsubsection{Operating mode selection: Natural ventilation or Mechanical Heating or Cooling}

302 The upper and the lower temperature boundaries of the thermal acceptability limits retrieved

303 from adaptive thermal comfort standard (ASHRAE 55 [43]) were calculated dynamically in order to select the mode of operation. The running mean temperature, $\mathrm{T}_{r m}$, was calculated each day as a function of the average temperatures of the previous seven days. These data were monitored by the weather station described in Section 3.2 and located just outside the case study house. The upper and the lower boundaries of the adaptive thermal comfort band represent the daily limits in which the natural ventilation mode can be activated, and they were

309 calculated as in Eq.1.

$310 \quad\left\{\begin{array}{l}T_{N V, \max }=0.31 \cdot T_{r m}+21.3 \\ T_{N V, \text { min }}=0.31 \cdot T_{r m}+14.3\end{array}\right.$

311 The set-point selected for the thermal regulation to be achieved in natural ventilation mode was

312 evaluated as the mean value of the adaptive thermal comfort temperature limits, as presented 
313 in Eq.2. This operation was performed daily, at midnight.

$314 T_{N V, \text { set }}=\left(T_{N V, \min }+T_{N V, \max }\right) / 2$

315 An example of the evolution of the indoor set-point temperature in natural ventilation mode is

316 shown in Figure 3 over a period of seven days. It can be observed that the set-point changed

317 dynamically according to the running mean temperature.

\subsubsection{Natural ventilation: flow network solution and calculation of Air Change Rate} for each opening percentage

The optimal opening percentage of the windows was calculated based on the solution of a simplified flow network considering only wind-driven ventilation (buoyancy effects were not considered). The controller first calculated the surface-averaged wall pressure coefficients using polynomial interpolation of the curves recommended by ASHRAE Fundamentals Handbook [44], and from the measured wind speed and direction. The opening area of the windows was then calculated as in Eq. 3. The area of each window $i$ open at a percentage level $j$ was calculated as:

$A_{j}=\left[1-\cos \left(\operatorname{asin}\left(l_{c} \cdot w p_{j}\right)\right)\right] \cdot L \cdot H$

Where $l_{c}$ is the length of the window chain, $w p_{j}$ is the window opening percentage at each level $j, L$ and $H$ are the length and width of each window as reported in Table 1.

The solution of the flow network allowed the controller to compute the predicted number of volume air changes per control time-step $\left(\beta_{j}\right)$, at each opening level $j$. This value is numerically limited between 0 and 1, where 1 represents the full air exchange.

\subsubsection{Natural ventilation: calculation of air temperature mix and selection of optimal} opening percentage

In natural ventilation mode, the controller regulated the internal operative temperature resulting 
336 from the mixing of indoor and outdoor temperature by adjusting the opening percentage of the

337 operable windows. The comfort based controller aimed to predict the indoor operative temperature at the next control time-step (considered one hour long) for each possible operable window opening position.

340 Since the mean radiant temperature will change more slowly compared to the indoor air

341 temperature, and generally a significant variation of the internal surface wall temperature

342 would not be expected to occur during a control time step, it was assumed to be constant for

343 the calculation of the operative temperature at the next time step.

344 The predicted indoor air temperature $T_{a, j}$ was therefore the only necessary parameter to be 345 calculated for the next control time step; $T_{a, j}$ was evaluated as a straightforward mixing of the 346 two air volumes at indoor and outdoor temperature, as shown in Eq.4.

$T_{a, j}=\left(1-\beta_{j}\right) \cdot T_{a}+\beta_{j} \cdot T_{\text {out }}$

Where $T_{a}$, and $T_{\text {out }}$ are the current internal and external air temperatures, and $\beta_{j}$ the aforementioned predicted number of volume air changes. The operative temperature $T_{o, j}$ was then calculated as the mean between the indoor air and mean radiant temperature.

351 The optimal window opening position $\left(j^{*}\right)$ was the one that minimises the distance between the predicted indoor operative temperature at the next control time step and the natural ventilation set-point, as per Eq. 5.

$j^{*}=\operatorname{argmin}\left(\left|T_{o, j}-T_{N V, \text { set }}\right|\right)$

357 In the case where the indoor conditions were outside the adaptive thermal comfort limits, mechanical heating or cooling was activated. In this operating mode, the set-point for the 
359 internal air temperature was selected by reversing Fanger's PMV comfort index. The house

360 HVAC system configuration allowed only the indoor air temperature to be used as adjustable

361 input variable. The other environmental variables affecting the PMV index (i.e., internal mean

362 radiant temperature, air velocity, and relative humidity) were monitored and affect the comfort

363 dynamics as measured disturbances. Significant changes of the measured disturbances were

364 not expected in short span represented by the control time step. The optimal temperature set-

365 point was calculated as the dry-bulb temperature that would result in a PMV level at the border

366 of a “comfort class B” range (PMV $= \pm 0.5$, representing $P M V_{\text {set,h }}$ and $\mathrm{PMV}_{\text {set,c }}$ ) in accordance

367 with ref. [45]. The set-point for the indoor air temperature was calculated iteratively using the

368 bisection method.

369 In the present experimental study, the tests were conducted assuming a clothing index equal to $370 \mathrm{I}_{\text {clo }}=1$ clo (i.e. typical heating season clothing [46]). The metabolic rate was set to $\mathrm{M}=1.2$

371 met, which is the value indicated for dwelling sedentary activity [46]. These values could be

372 adjusted depending on the specific application or in accordance with the occupants'

373 requirements. In the simulations performed in the various seasons, the clothing index was

374 considered to be equal to 1 clo in winter, 0.5 clo in summer and 0.75 clo in the middle seasons. 


\subsection{Description of the case study building}

377 An experimental test of the developed controller was completed using a case study high performance single family dwelling, namely the Team UOW “Illawarra Flame” house that won the 2013 Solar Decathlon China competition. This building features a mixed-mode ventilation system that utilises both natural ventilation and mechanical heating or cooling. The controller of the house was original a simple control logic commonly used in Australia to handle natural and mechanical ventilation as described in Section 2.1. This was the baseline controller used for comparison in this study to test the performance of the new comfort-oriented control strategy. The house was located at the Innovation Campus of the University of Wollongong in Wollongong, New South Wales, Australia. External and internal views of the house are shown in Figure 4. The building is located in Climate Zone 5 - warm temperate in the Australian

National Construction Code climate classifications. This climatic zone is characterised by low temperature difference between night and day, mild winter conditions, comfortable outdoor temperatures and moderate humidity. These weather conditions are suitable for exploiting natural ventilation benefits, especially during the swing seasons.

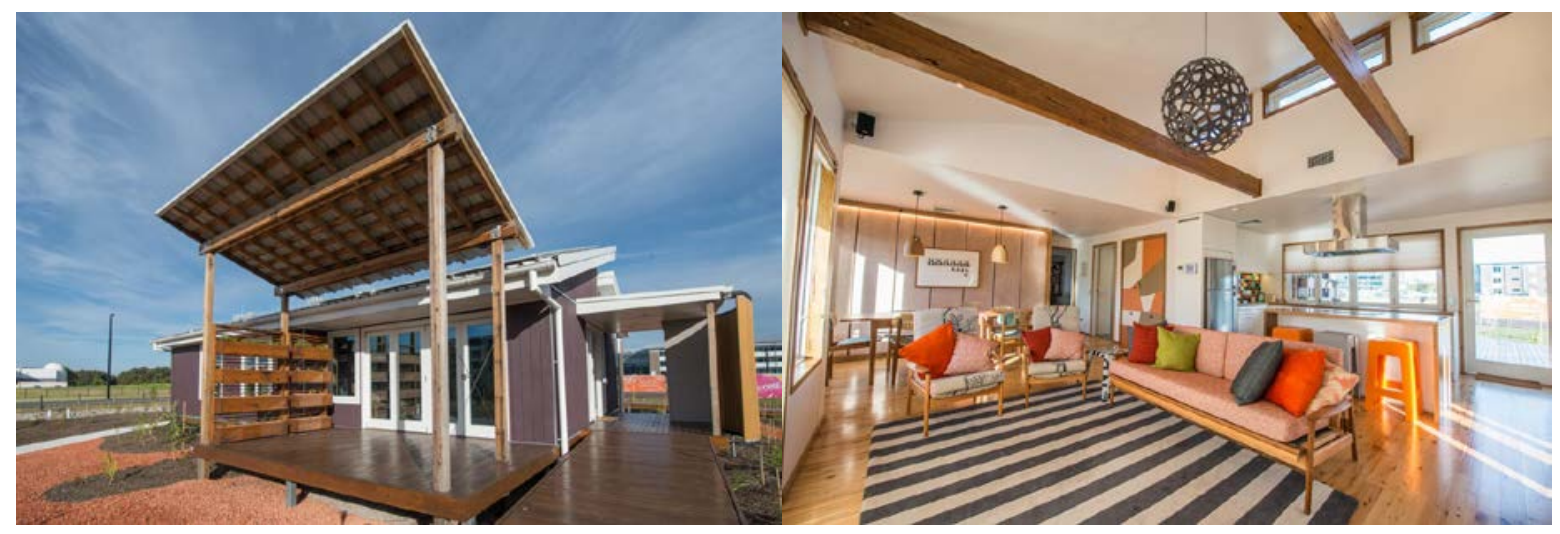


395 The overall thermal resistance of the opaque components of the building (ceiling, walls, and 396 floors) was approximately $6.0 \mathrm{~m}^{2} \mathrm{~K}^{-1} \mathrm{~W}^{-1}$. Windows are timber-framed and characterised by a 397 Solar Heat Gain Coefficient (SHGC) equal to 0.3 and a U-Value lower than $1.5 \mathrm{Wm}^{-2} \mathrm{~K}^{-1}$. A 398 degree of thermal mass was added to the lightweight timber structure with a $2.2 \mathrm{~m} \mathrm{x} 3.2 \mathrm{~m} \mathrm{x}$ $3990.1 \mathrm{~m}$ thick concrete panel added to an internal living room wall. A shading system in the form 400 of fixed slatted timber screen was installed on the east and west facades of the house to reduce excessive solar heat gains. The indoor environments can be conditioned using an air-based system equipped with a reversible heat pump. The nominal heating and cooling design capacity 403 of the mechanical system is $7 \mathrm{~kW}$.

404 One of the key targets of the original Solar Decathlon project was to achieve net-zero energy 405 consumption throughout the year. To achieve this target, a number of energy efficient passive 406 and active measures were applied to the house, including the exploitation of natural ventilation.

407 The house was a suitable case study for testing a mixed-mode ventilation building as the building controller has the flexibility to be interfaced to each individual HVAC component, as

409 well as with external sensors. The window opening regulation is adjustable at $1 \%$ intervals 410 allowing effective control of natural ventilation flow rates. The mechanical heating or cooling 411 is provided by a $7 \mathrm{~kW}$ conventional reverse cycle ducted air conditioner, with a temperature 412 set-point resolution of $1^{\circ} \mathrm{C}$. The set-point is determined by regulating a high level controller. 413 The HVAC component operates as a single-zone system that is entirely regulated by the 414 thermostat located in the living room. This is a traditional set-up for residential dwellings in 415 the area of the study.

416 A plan view of the house layout highlighting the operable windows locations (positions A to E 417 at lower level and windows $\mathrm{H}$ at upper level) is presented in Figure 5. The operable windows 418 are of various typologies and sizes. The existing controller only enables a simultaneous 
operation of all the windows together. A summary of the windows characteristics that are used in Eq. 3 is reported in Table 1.

Table 1. Illawarra Flame house - windows characteristics.

\begin{tabular}{ccccc}
\hline Window & Type & L [m] & H [m] & lc [m] \\
\hline A & Awning & 0.80 & 1.50 & 0.30 \\
B & Casement & 0.54 & 1.50 & 0.30 \\
C & Casement & 0.54 & 1.40 & 0.30 \\
D & Awning & 0.40 & 1.40 & 0.30 \\
E & Awning & 0.40 & 1.40 & 0.30 \\
H & Awning & 1.30 & 0.30 & 0.30 \\
\hline
\end{tabular}

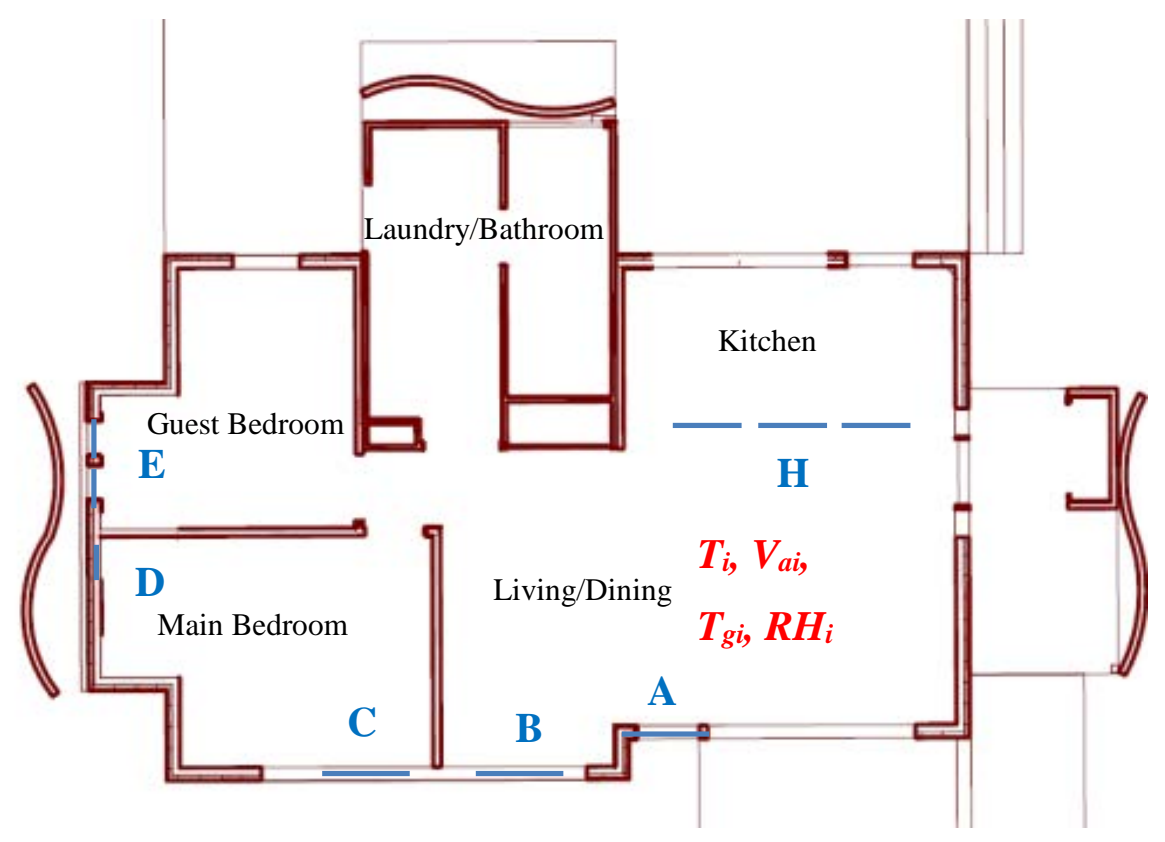
its sensing unit (using a Raspberry Pi and relevant sensors that are discussed in Section 3.2) is shown in red.

\subsubsection{Building Management Control System (BMCS) architecture and integration}

428 The control system of the Illawarra Flame house was designed to accommodate the objectives and constraints of the overall Solar Decathlon project, and to be capable of controlling lighting systems, operable windows and the complex HVAC system. The BMCS is also capable of monitoring temperatures, energy consumption, electricity generation and flow rates, and can 
432 effectively report this information to the user via a graphical interface. The system is based on 433 Clipsal C-Bus components.

434 A supervisory BMCS (Tridium Niagara JACE) was integrated with the local low level control system, to act as a data logger and a gateway to various communication languages, such as

436 Modbus and oBIX [47] networks.

437 The JACE controller also has the capability to over-ride the local controller of the reversecycle air conditioning unit, utilising a Modbus gateway, allowing the control system to dynamically change the operation mode of the HVAC system, the temperature set-point and the fan speed. The controllers of windows located at lower level (i.e., windows A to E), which adjust the window opening percentage, are also connected to the JACE controller via Modbus.

442 The architecture of the BMCS is shown in Figure 6 and is discussed below.

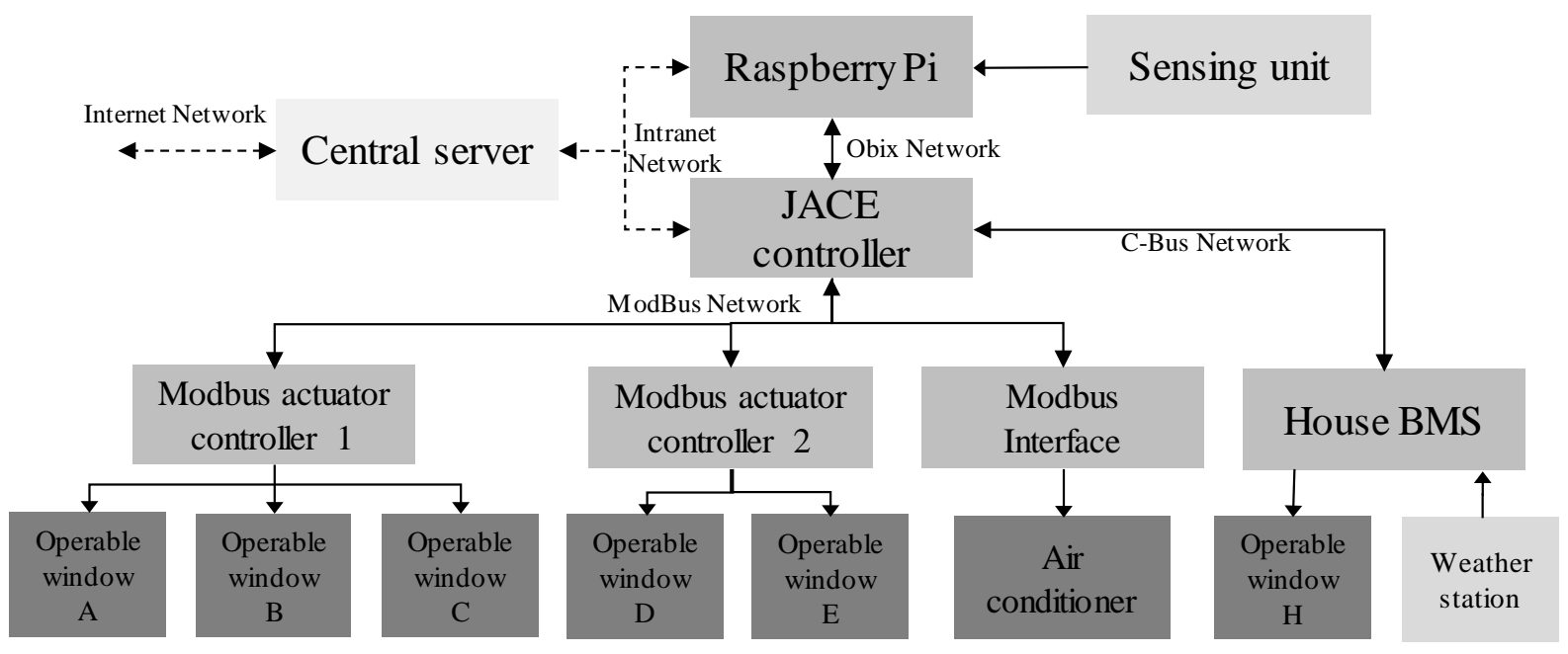

Figure 6: BMCS system integration, windows and air conditioning control schematic.

445 One of the goals of the current paper is to highlight the potential to run smart control algorithms on affordable control processors. A Raspberry Pi 3 model B was selected for this purpose. The Raspberry Pi is one of the most widespread single-board computers with a $1.2 \mathrm{GHz}$ quad-core ARMv8 processor and 1 GB of integrated RAM. The market offers many alternatives that are equivalent to this controller. The control algorithm was implemented using Python, which is a 
452

453

454

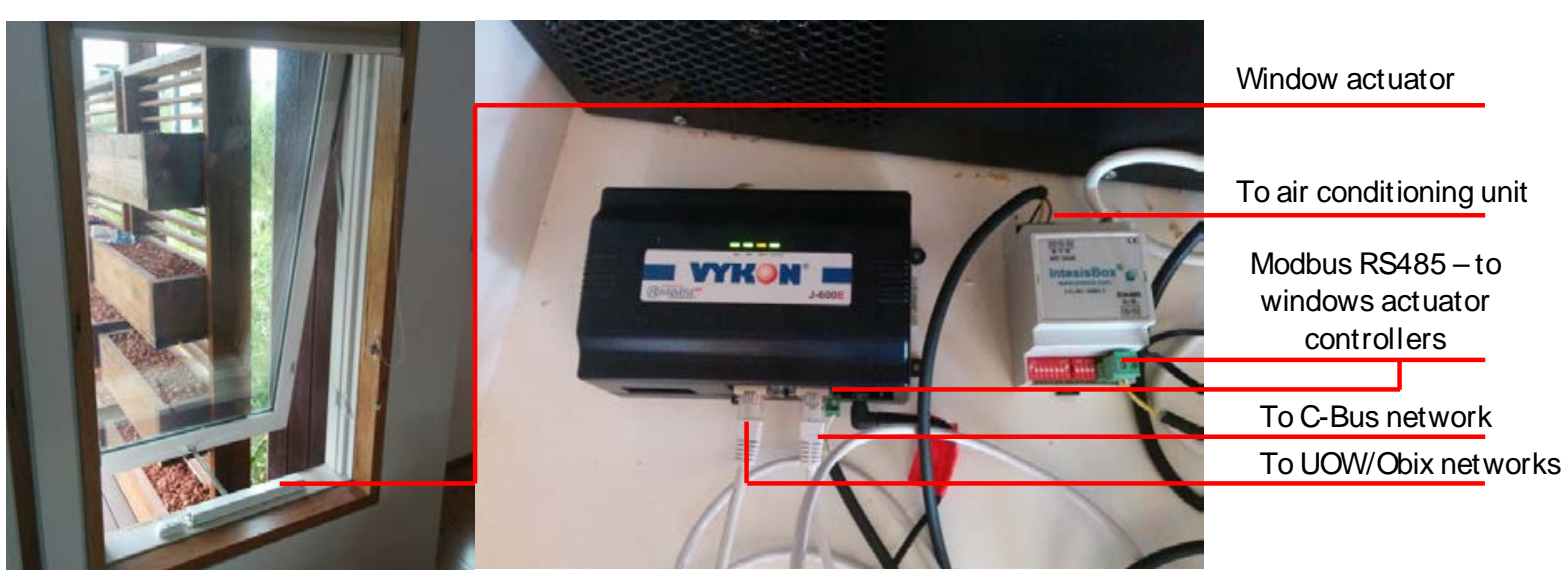

Figure 7: Window actuator (Window A) and JACE controller.

The python control algorithms implemented on the Raspberry pi are the same implemented in the simulation platform described in Section 2.4, with some of the variables of the array $\boldsymbol{x}^{*}(k)$ pre-processed on-board from the real-time measurements and with the outputs $\boldsymbol{u}^{*}(k)$ directly controlling the windows opening, air conditioning system set-point and operating mode.

\subsubsection{Monitoring instrumentation}

The outdoor weather conditions were monitored using a Davis Vantage Pro II Weather station, integrated through an RS232 connection to the C-Bus and JACE control units. The weather parameters considered by the control algorithm are: outdoor temperature (nominal accuracy \pm 1 ${ }^{\circ} \mathrm{C}$, range -40 to $65^{\circ} \mathrm{C}$ ), global horizontal solar radiation (nominal accuracy $\pm 5 \%$ of full scale, range up to $1800 \mathrm{~W} / \mathrm{m}^{2}$ ), wind speed (nominal accuracy $\pm 0.9 \mathrm{~m} / \mathrm{s}$, range 1 to $89 \mathrm{~m} / \mathrm{s}$ ), and wind direction (nominal accuracy $\pm 3^{\circ}$ ). The weather station was located on the roof of the controlled house (approximately $4 \mathrm{~m}$ height). Since the distance between the wind speed sensor and the opening height of the upper windows was less than $1 \mathrm{~m}$, the measured wind speed values were not adjusted for height differences. 
The indoor conditions were monitored using a sensing unit equipped with low cost sensors, directly connected to the Raspberry Pi unit (Figure 8). The sensors used were those required for the determination of the PMV index and their characteristics are listed in Table 2. The

471 location of the Raspberry Pi controller and the sensor units are highlighted in Figure 5. All the 472 sensors were placed at $1 \mathrm{~m}$ height.

473

474

475

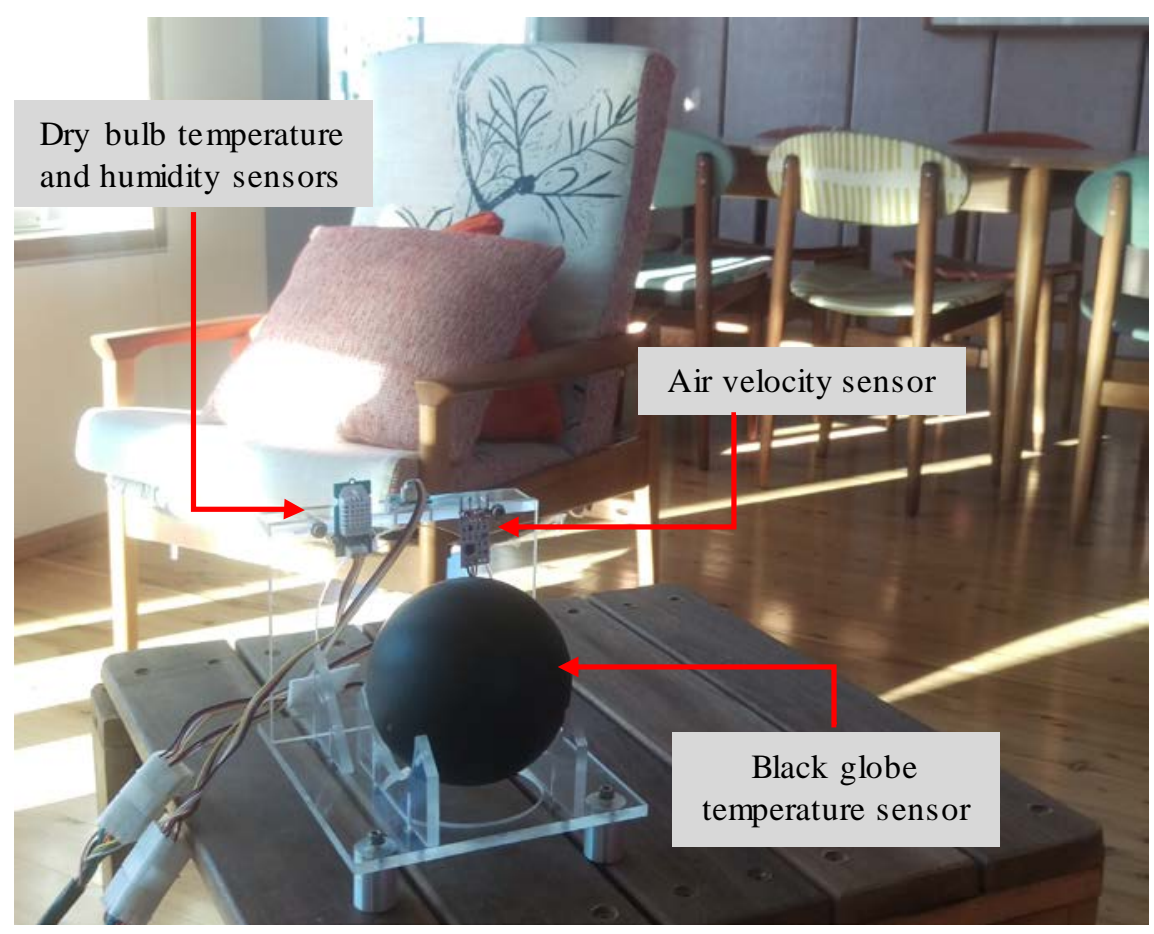

Figure 8: Raspberry Pi sensing unit

Table 2: Raspberry Pi sensor list

\begin{tabular}{lccc}
\hline Sensor & Variable & Accuracy & Type \\
\hline Indoor air temperature, & $T_{a}$ & $\pm 0.3^{\circ} \mathrm{C}$ & Thermistor - digital \\
Indoor relative humidity & $R H_{i}$ & $\pm 2 \%$ & Thermistor in a $100 \mathrm{~mm}$ \\
Black globe temperature & $T_{g i}$ & $\pm 0.3^{\circ} \mathrm{C}$ & diameter black copper sphere \\
Air velocity & $v_{w}$ & Not provided & Hot wire anemometer - analog \\
\hline
\end{tabular}

477 The sensors and the Raspberry Pi acquisition chain were calibrated against a high accuracy 478 sensors system, which met the requirements of ASHRAE 55 and ISO 7726:1988 standards.

479 The details of this system are presented in Table 3. 


\begin{tabular}{lccc}
\hline Sensor & Range & Accuracy & Type \\
\hline Indoor air temperature & $0-50^{\circ} \mathrm{C}$ & $\begin{array}{c}20^{\circ} \mathrm{C}= \pm 0.04^{\circ} \mathrm{C} \\
30^{\circ} \mathrm{C}= \pm 0.05^{\circ} \mathrm{C}\end{array}$ & RTD PT100 \\
& & $0-60 \%= \pm 2.5 \%$ & HUMICAP \\
Relative humidity & $0-95 \%$ & $0-80 \%= \pm 3.0 \%$ & $\begin{array}{c}\text { T-Type thermocouple in a } 40 \\
\text { mm diameter black copper }\end{array}$ \\
Black globe temperature & $0-50^{\circ} \mathrm{C}$ & $\begin{array}{c} \pm 0.4 \% \text { or } \\
\text { s. reading }\end{array}$ & $\begin{array}{c}\text { more } \\
\text { Air velocity }\end{array}$ \\
& $0.05-$ & $\begin{array}{c} \pm \% \text { reading } \\
\pm 1 \% \text { full scale } \\
\text { range }\end{array}$ & $\begin{array}{c}\text { Hot wire anemometer - } \\
\text { omnidirectional probe tip }\end{array}$ \\
\hline
\end{tabular}

482 The sensors allow the measurement of the variables that are required to calculate the PMV 483 index and the adaptive thermal comfort band. These measurements were either direct (e.g. 484 indoor air temperature, relative humidity, indoor air velocity) or determined using intermediate 485 calculations. The indoor mean radiant temperature was evaluated with a black globe 486 thermometer, and from the measurements of indoor air temperature and indoor air velocity to 487 remove convective effects. The experiments were undertaken with control and measurement 488 time steps both being equal to 5 minutes. During the experimental campaign, the internal doors 489 remained open, and the controller regulated the spaces as a single-zone.

\subsection{Simulation Platform for Controller Benchmarking}

491 In order to benchmark the performance of the baseline and the adaptive comfort controller, an 492 ad-hoc simulation platform was developed, building on the previous work by some of the 493 current authors [22,48]. Simulations were deemed necessary for validation of the experimental 494 results, allowing detailed comparison of the performance of the comfort-oriented controller 495 under the same boundary conditions as the baseline controller.

496 To achieve a time-step coupling between a building energy performance simulation software 497 and a complex controller, the Building Control Virtual Test Bed (BCVTB) tool [49] was used 

as an interface. We have modified the standard ESP-r building simulation software code to enable sending the array of measurements, $\boldsymbol{x}(k)$, necessary for the controller to compute the optimal natural or mechanical ventilation strategy via the BCVTB socket, and to receive the required inputs, $\boldsymbol{u}(\mathrm{k})$, from the controller to operate the building systems (windows and

502 mechanical heating/cooling). The information sent from ESP-r was pre-processed by the 503 BCVTB, in order to be able to send computed variables (such as $T_{r m}$ ) in the array of measurements $\boldsymbol{x}^{*}(k)$ to the controller, which was programmed in Python. A schematic of this software integration is presented in Figure 9.

506 The controller input array was $x^{*}(k)=\left[T i, R H_{i}, v_{w}, \overline{T_{r}}, T_{a}, R H_{o}, T_{r m}, \theta, I_{c l}\right]$ and the output array was $\boldsymbol{u}(\mathrm{k})=\left[j^{*}, T_{A C \text {,set }}\right.$ mode $]$. The indoor air velocity, which was used by the controller to calculate the optimal air temperature set-point when in mechanical ventilation mode, was assumed to be constant and equal to $0.2 \mathrm{~m} / \mathrm{s}$ for PMV calculations [43].

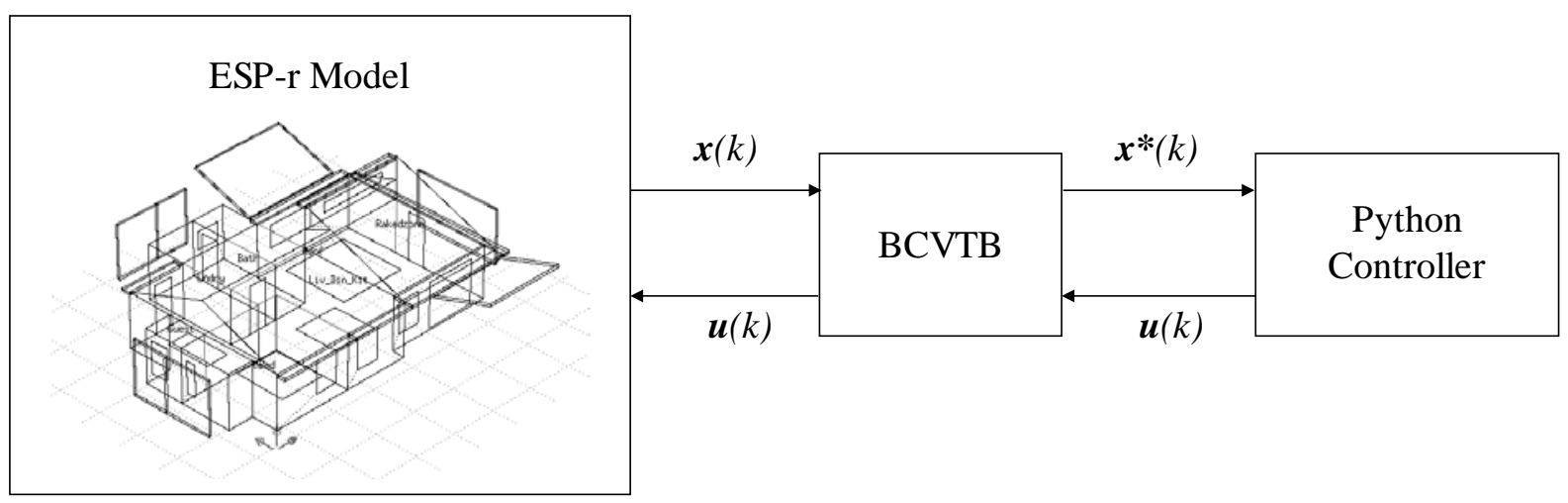

512 Figure 9: Simulation Platform software integration using a model of the case study building. 


\section{Results and Discussion}

\subsection{Simulation Results}

517 A simulation was completed for both controllers using International the Weather for Energy

518 Calculations (IWEC) file over a summer month (January), a winter month (July) and an autumn

519 month (April). A portion of the results for each month is reported in Figure 10, Figure 11, and

520 Figure 12 respectively. A complete summary of the results is provided in Section 4.3.

521 Each figure contains three sub-figures: the first reports the indoor and outdoor temperature conditions, air conditioning system set-point and the adaptive thermal comfort boundaries; the seconds one displays the associated PMV values and the boundaries of ISO Class B acceptability range; and the last presents the control inputs to the house (heating, cooling, or opening percentage of windows). The shaded areas of the first two subplots of each figure highlight the periods when mechanical conditioning was operating.

In both cases shown in Figure 10 and Figure 11, the comfort-oriented controller outperformed the baseline controller in terms of both maintaining comfort and reduced energy consumption. In Figure 10a, the windows are either fully open or partially open for the majority of the time.

530 This is due to baseline controller calculating the operation of the windows based on the outdoor temperature only. In the situation shown, the windows are kept open even when it would not be advisable to do so, as the indoor temperature is at the lower end of the comfort band and the outdoor air is cooler (e.g. between the $23^{\text {rd }}$ and $26^{\text {th }}$ of January). This resulted in indoor

534 conditions outside the adaptive thermal comfort band, on the cold side, while in natural

535 ventilation mode. For the same period the windows operated considerably less frequently when

536 the comfort-oriented controller was employed, shown in Figure 10b, especially in the middle 537 of the period presented. 
538 During the period shown, the baseline controller activated the cooling mode on two occasions, 539 despite the indoor air temperature remaining within the comfort range, while the comfort540 oriented controller did not utilise mechanical conditioning for the entire period.

541 A similar behaviour in natural ventilation mode can also be noticed during the middle season

542 in April (Figure $11-14^{\text {th }}$ and $15^{\text {th }}$ of April), during which the baseline controller tended to 543 overcool the building towards the bottom of the comfort range. Furthermore, when heating and 544 cooling was needed, the comfort-oriented controller imposed a higher indoor set-point 545 temperature compared to the baseline controller in order to better achieve the PMV target. 
a)
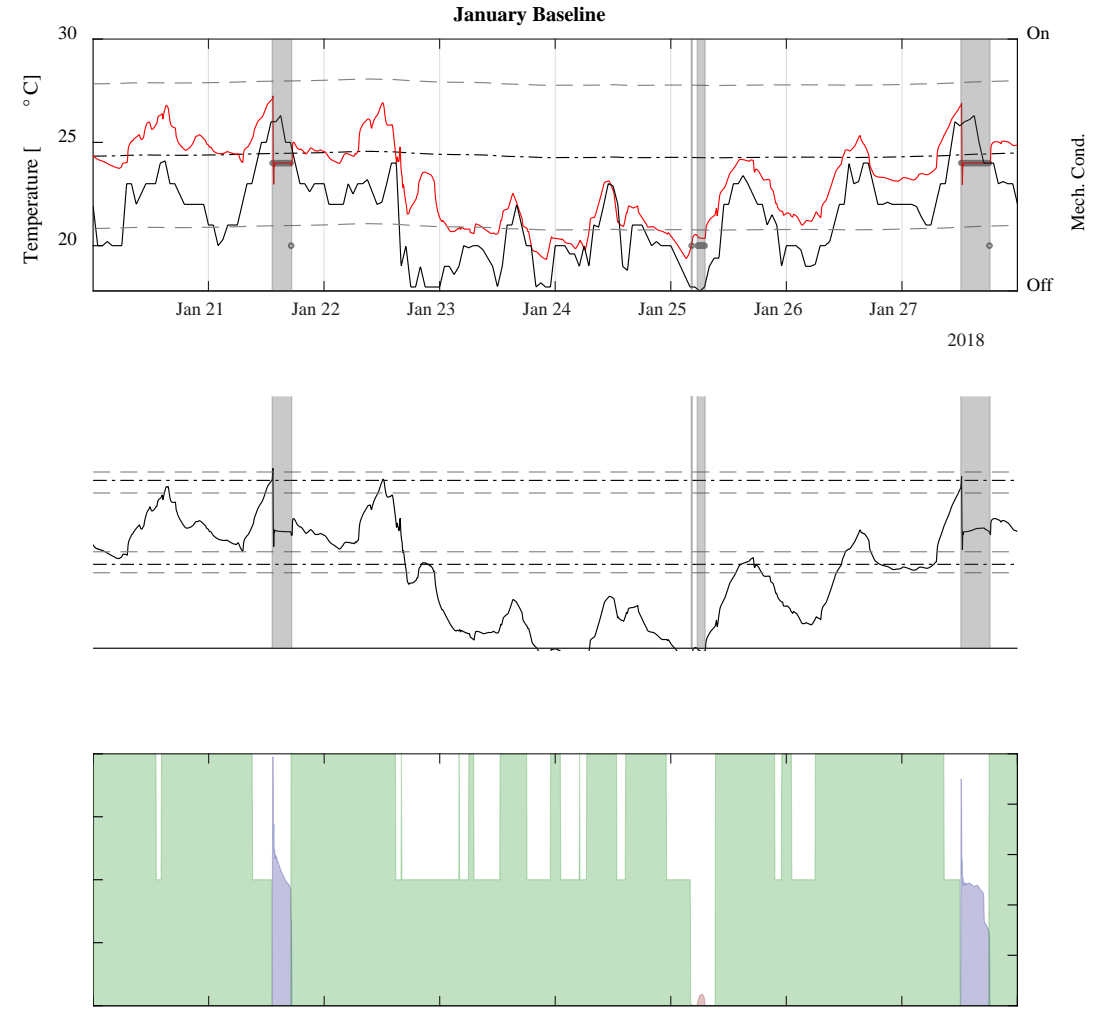

b)
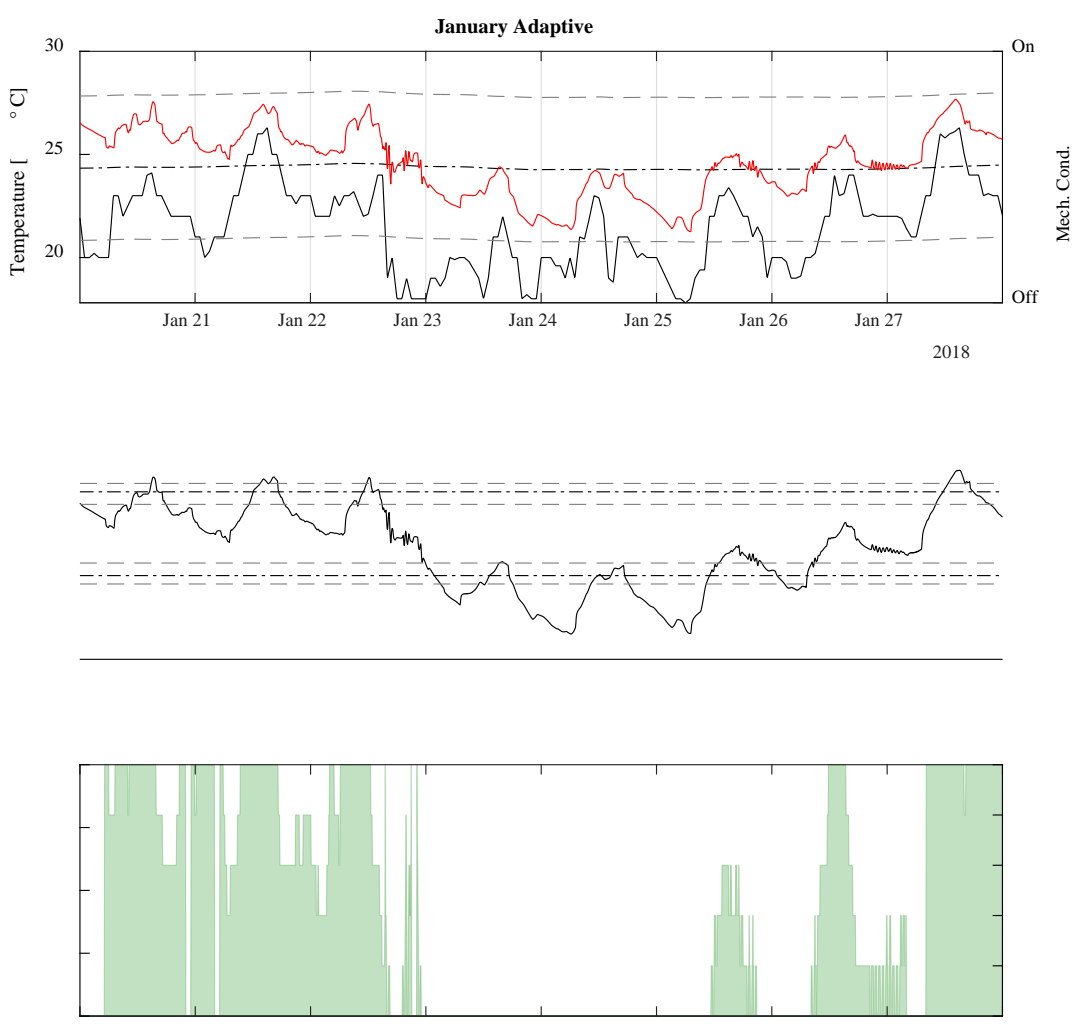

Figure 10: Simulation results, January, Sydney. a) baseline controller; b) comfort-oriented controller. 
a)
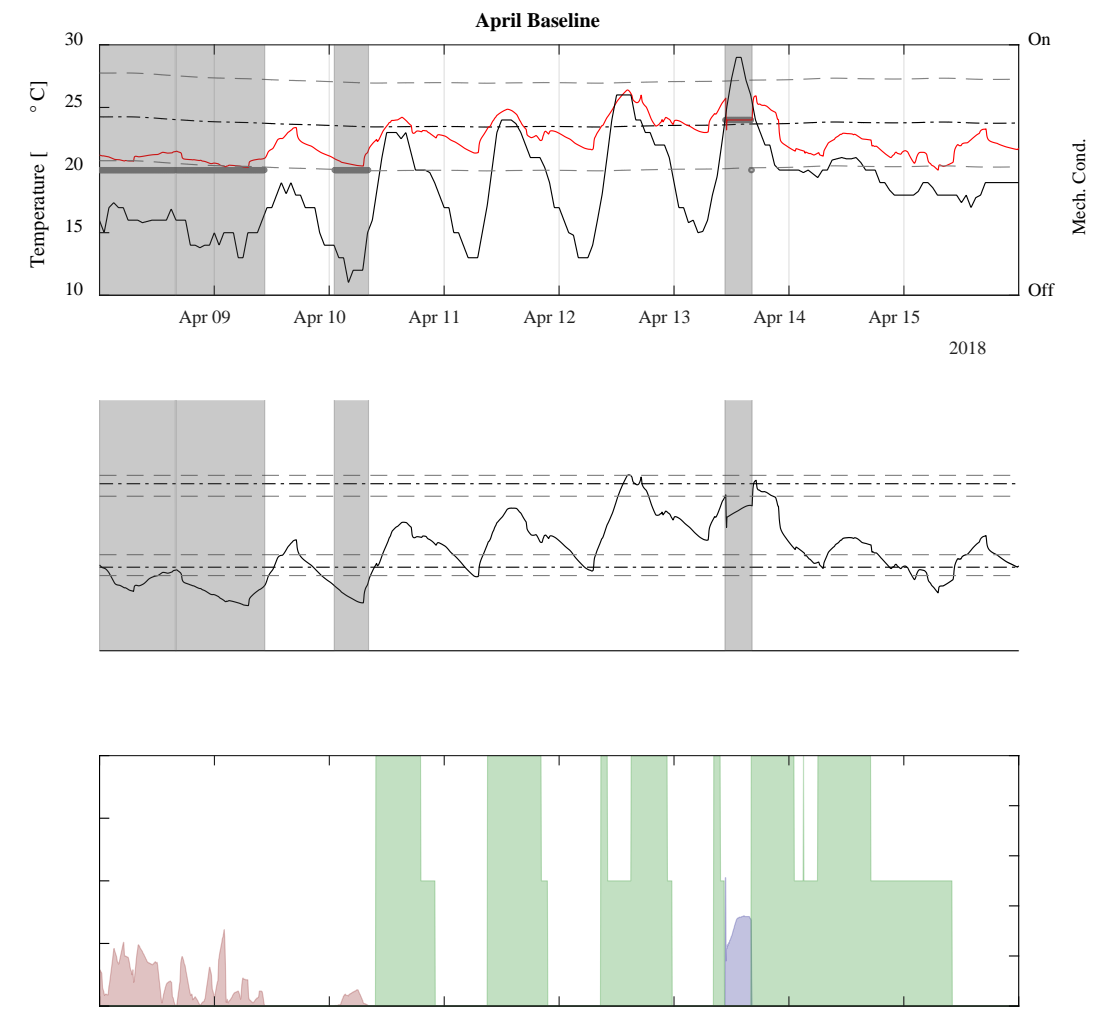

551

b)
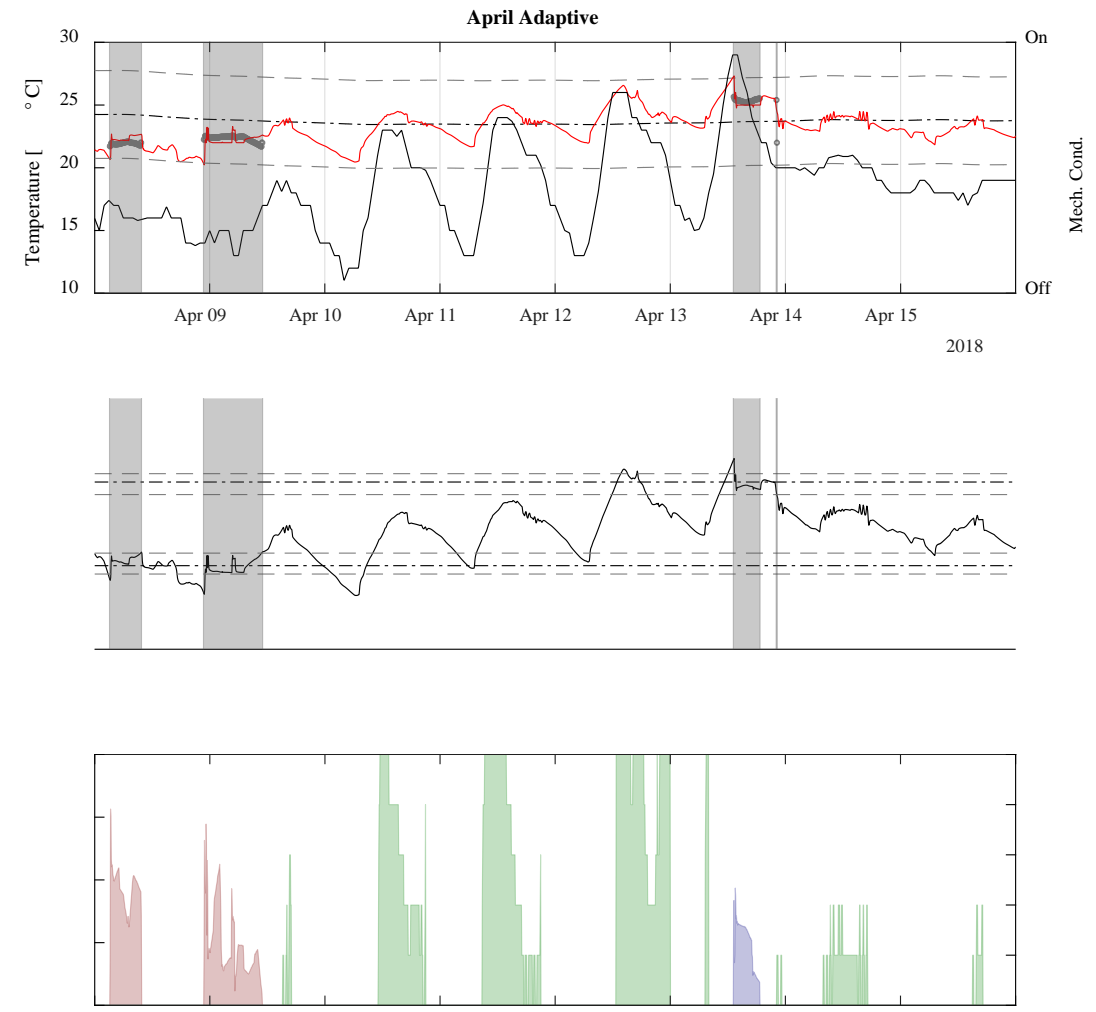

Figure 11: Simulation results, April, Sydney. a) baseline controller; b) comfort-oriented controller. 
555 In winter conditions, mechanical heating was generally needed in the case study building, as 556 shown in both Figure 12a and Figure 12b. Despite maintaining a relatively constant 557 temperature, as shown in Figure 12a, the baseline controller was not able to ensure that the 558 PMV level remained within the recommended range, due to the other dynamically changing 559 variables included in the PMV calculation. The comfort-oriented controller was able to manage 560 this issue by dynamically varying the heating set-point (e.g. $12^{\text {th }}$ of July) to maintain a more 561 constant PMV, as shown in Figure 12b. Consequently, there was an improvement of occupants’ 562 thermal comfort with just a slight increase of the overall energy consumption (approximately 563 6\%, as presented in Table 4). Quantitative simulation results are summarised and discussed in 564 Section 4.3 and more specifically in Table 4, together with the experimental results of this 565 study. 

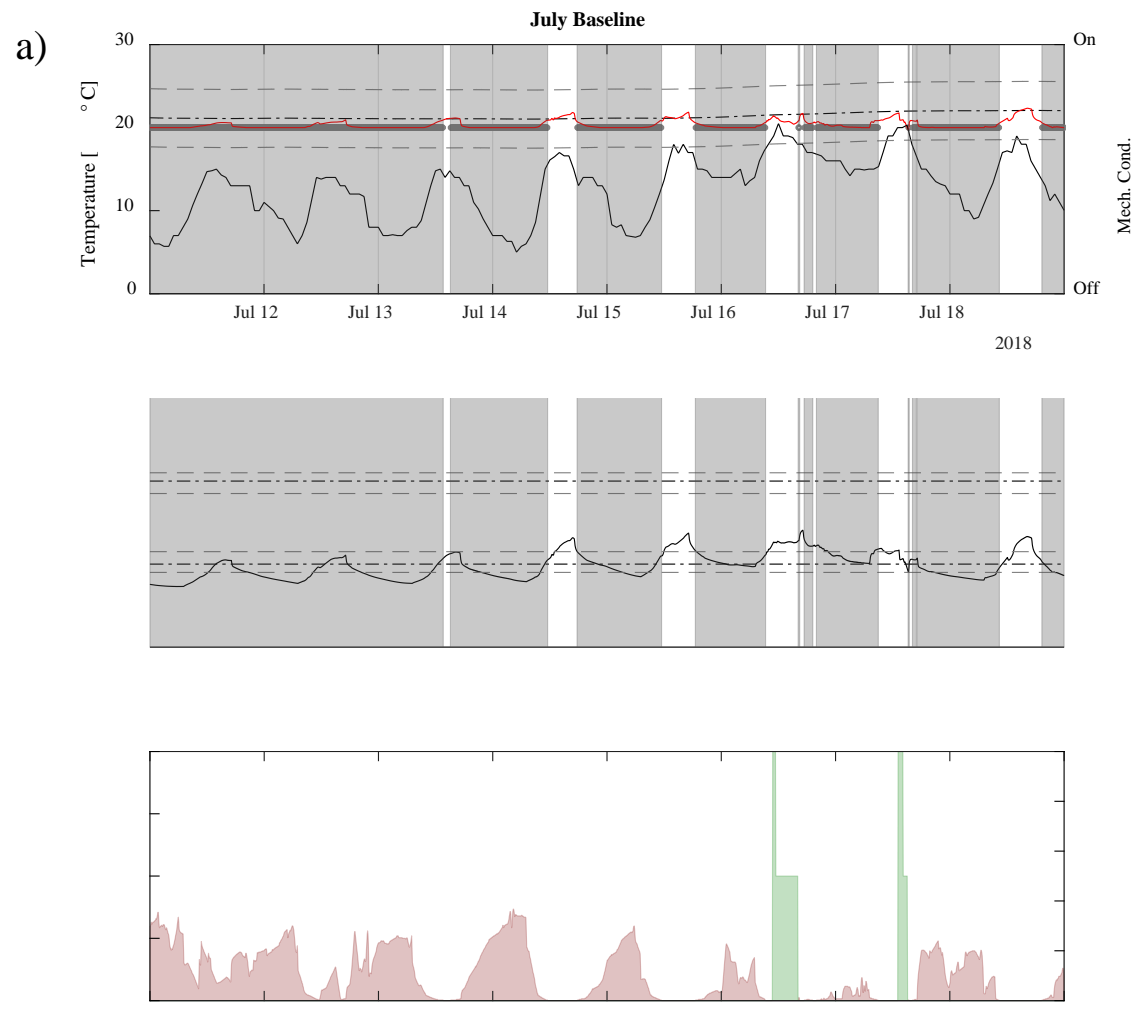

b)
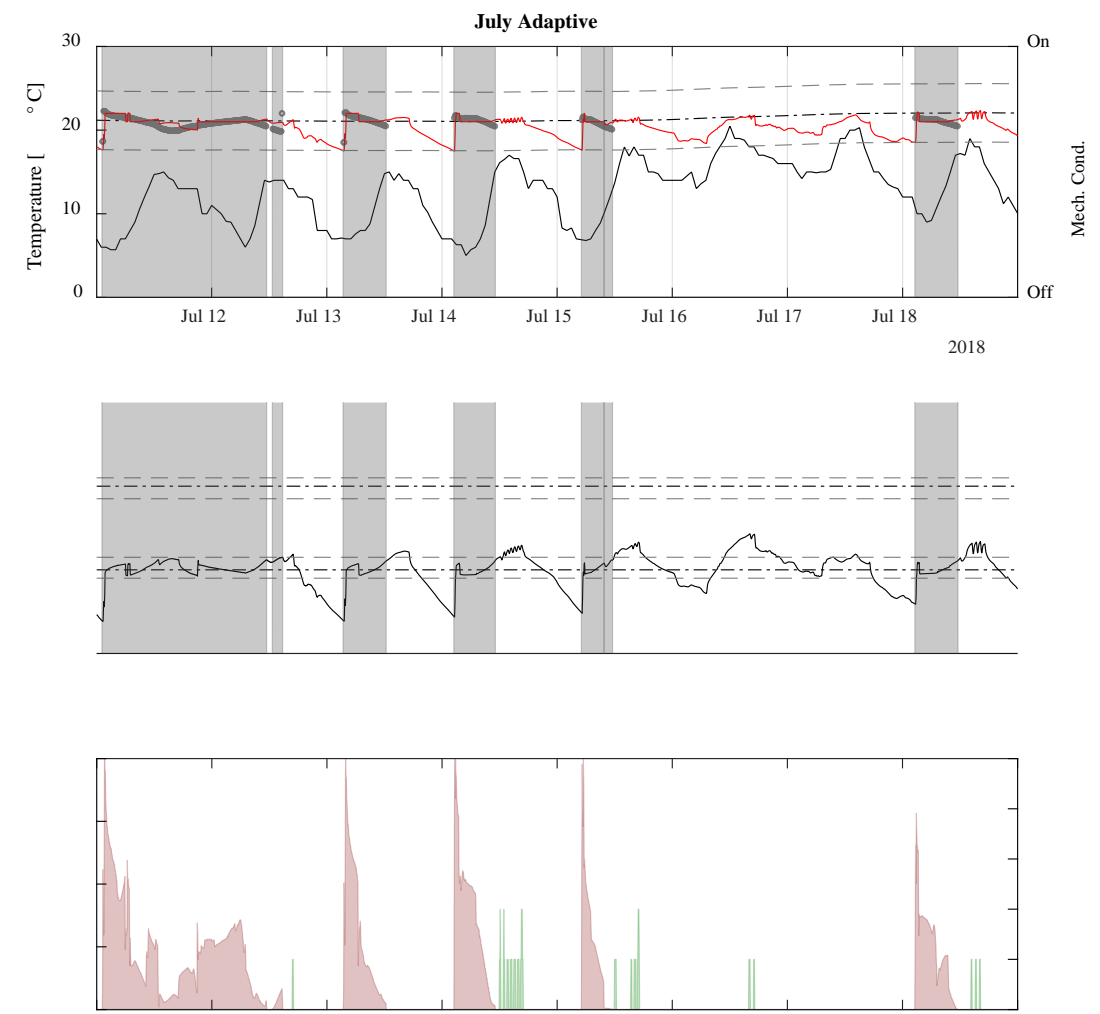

Figure 12: Simulation results, July, Sydney. a) baseline controller; b) comfort-oriented controller. 


\subsection{Experimental Results}

571 Both the baseline and the comfort-oriented control strategies were tested on the Illawarra Flame

572 house using the infrastructure presented in Section 3.2. The baseline controller was tested

573 between the $21^{\text {st }}$ and the $23^{\text {rd }}$ of April 2018 and the results are reported in Figure 13 . The

574 comfort-oriented controller was tested between the $26^{\text {th }}$ and the $29^{\text {th }}$ of May 2018 (Test 1 ) and

575 the $30^{\text {th }}$ and $31^{\text {st }}$ of May 2018 (Test 2), and the results are presented in Figure 14 and Figure 15

576 respectively (the test was interrupted on $29^{\text {th }}$ of May due to other issues with the house). Figures

577 are organised in the same way as that used for the simulations.

578 Although the baseline controller was generally capable of maintaining the indoor operative

579 temperature within the adaptive thermal comfort range, as shown in Figure 13 the temperature

580 was mostly close to the lower limit of the adaptive acceptability range, for example between

$58111 \mathrm{am}$ and $11 \mathrm{pm}$ on the $21^{\text {st }}$ of April. This result is also observed in the January and April

582 simulation results. This lower internal temperature often resulted in heating being required

583 shortly afterwards. 

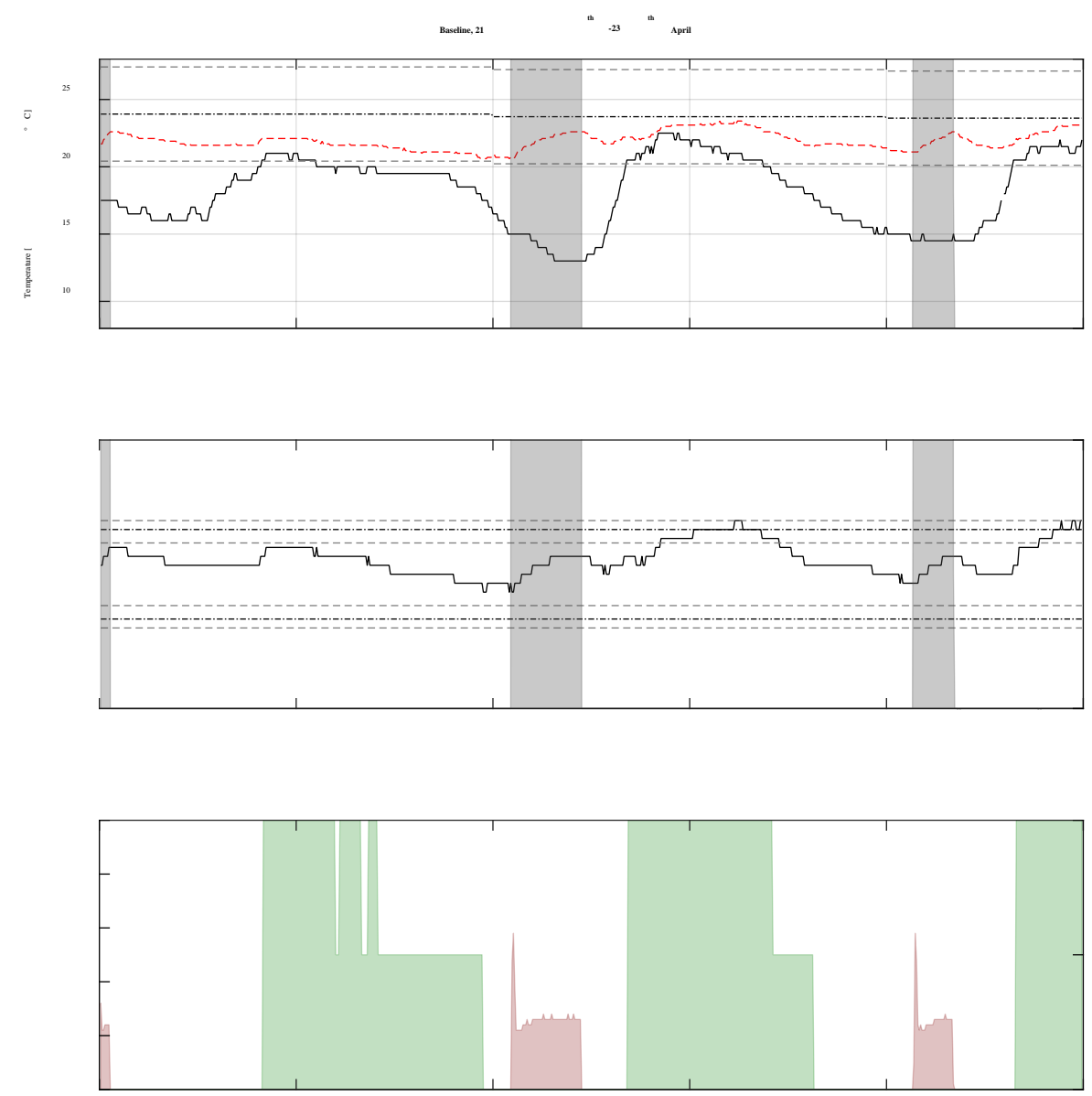

584

585

Figure 13: Baseline controller: experimental test, $21^{\text {st }}-23^{\text {th }}$ April 2018

586 Whilst the baseline control logic used both the outdoor and indoor temperatures as input

587 parameters, these variables were treated as independent. This leads to less optimal thermal comfort levels than could have been achieved if the windows were kept shut during the above example on the $21^{\text {st }}$ of April. It also resulted in higher energy consumption, due to the need for mechanical heating overnight.

591 The PMV levels recorded during this test are reported in the lower subplot of Figure 13. It

592 should be re-iterated that PMV is only indicative of comfort for periods of mechanical

593 ventilation. The indoor air temperature is the only parameter affecting the PMV directly manipulated by the mechanical heating system. Given that the lower the set-point of indoor air temperature, the lower the energy use for space heating is, the PMV should be maintained as 
596 close as possible to the lower acceptable bound during the heating season. For a comfort Class

597 B building this lower acceptable PMV level is equal to -0.5. In Figure 13 the PMV levels are

598 considerably above the minimum required level for a Class B building, and exceed 0 during

599 the periods of mechanical heating. The increase of PMV to levels above 0 was due to the

600 internal dead-bands of the heat pump controller, which resulted to indoor temperatures around

$60122^{\circ} \mathrm{C}$ even if the set-point during the heating operation was $20^{\circ} \mathrm{C}$.

602 The results for the comfort-oriented controller test presented in Figure 14 refer to relatively

603 warm days where cooling was generally needed during the day and heating during the night,

604 similarly to the period of the test with the baseline controller. During this testing period, the

605 indoor temperature remained within the adaptive comfort band. The test started in relatively

606 cold conditions, with the controller in heating mode for the first hours of the test. During these

607 first hours, the controller adjusted the heat pump set-point to maintain a constant PMV value. 

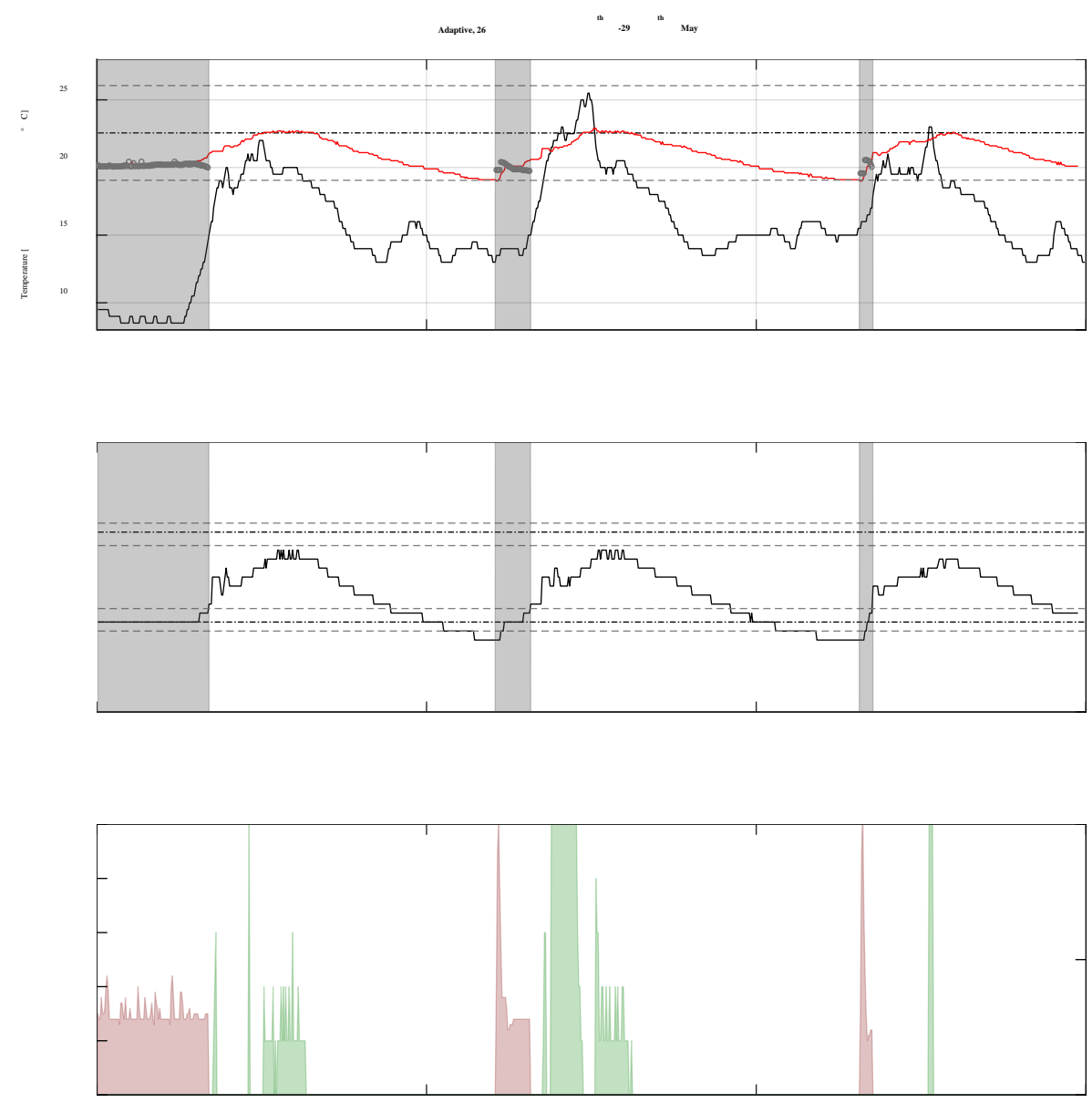

608

609 Figure 14: Comfort-oriented controller: experimental test during relatively warm days, $26^{\text {th }}$ 610 $29^{\text {th }}$ May 2018.

611 When natural ventilation mode operated (e.g. around 12:00 of the $26^{\text {th }}$ of May), the controller

612 effectively modulated the window opening percentage to keep the indoor temperature steady

613 at the defined set-point in the middle of the adaptive comfort band. The windows were opened

614 to regulate the indoor temperature for cooling purposes during the day of the $26^{\text {th }}$ of May.

615 During the second day (i.e., $27^{\text {th }}$ of May), mechanical heating was needed for the first part of

616 the day. Once the external conditions were appropriate, the system switched to natural

617 ventilation mode and opened the window because the outdoor temperature was higher than the

618 indoor. When the indoor temperature reached the natural ventilation set-point $\mathrm{T}_{\mathrm{NV} \text {,set, }}$ the

619 outdoor temperature was higher than the indoor one and the controller closed the windows to

620 avoid overheating (27 $7^{\text {th }}$ of May, 12:00). When the outdoor temperature decreased towards the 
621 end of the afternoon of the same day, the controller started to modulate the windows opening to provide a minimal amount of natural cooling to keep the indoor temperature close to the set-

623 point. During the third day (i.e., $28^{\text {th }}$ of May), the windows were only open when the outdoor

624 temperature sharply increased during the afternoon for a short amount of time (28 $8^{\text {th }}$ of May, 625 12:00), in an attempt to bring the indoor temperature closer to the middle of the adaptive 626 comfort band set-point.
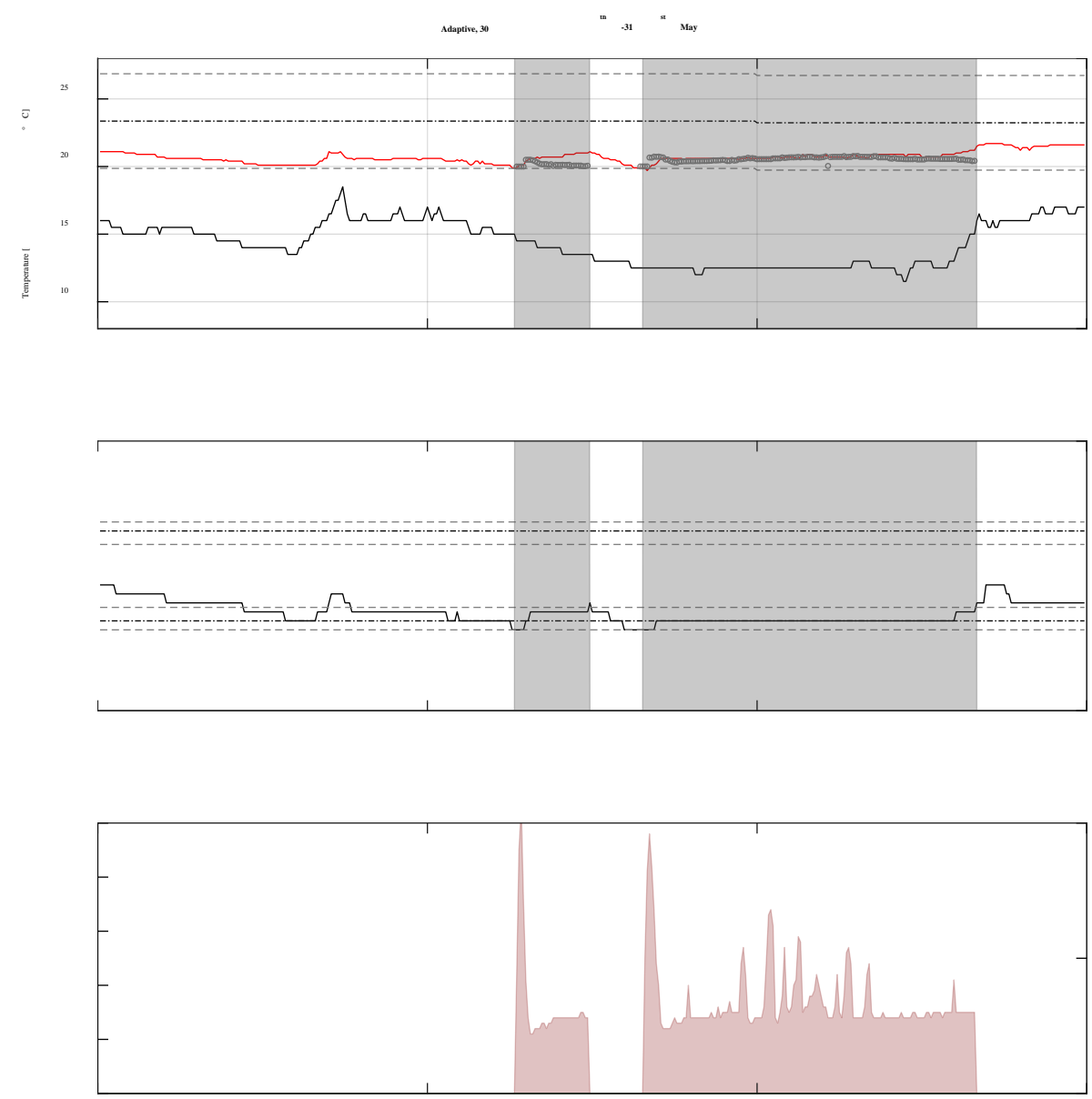

Figure 15: Comfort-oriented controller: experimental test during relatively cold days, $30^{\text {th }}$ $31^{\text {st }}$ May 2018.

630 The results presented in Figure 15 refer to relatively cold days, when mechanical heating was mostly needed. Observing the upper and lower subplots, it can be seen that the controller dynamically adjusted the heat pump set-point to keep a constant PMV value and better control the heating request. In the third subplot it can be seen that during the first heating operation the 
634 PMV slightly increased above the required set-point, and the controller responded by reducing

635 the temperature set-point to restore the PMV to the correct level. During the second heating

636 period, the controller maintains the PMV level constant at the set-point for the entire period.

$637 \quad 4.3$ Results summary

638 The simulated and experimental tests conducted in this study provide an effective

639 demonstration of the possibility to integrate an advanced control logic for mixed mode

640 ventilation on an embedded controller. An indication of the performance in terms of

641 maintaining comfort during the tests has been shown by calculating the cumulative deviation

642 of either:

643

i) the indoor operative temperature from the middle of the adaptive thermal comfort

644 band, during natural ventilation operation mode, or;

645

ii) the indoor PMV from the objective level of \pm 0.5 of the boundary of a comfort Class

646 B building, during mechanical ventilation mode.

647 In both cases deviation below or above this objective is equally penalised as loss of thermal 648 comfort.

649 The specific Key Performance Indicators, measuring a deviation from the ideal temperature or

650 PMV set-points, used to evaluate the controller performance in terms of satisfaction of

651 occupants' comfort requirements were:

$$
\begin{aligned}
& \varepsilon_{P M V, \text { heat }}=\frac{\sum_{k=0}^{N_{m}}\left|P M V_{i, k}-P M V_{\text {set }, k}\right|}{N_{\text {heat }}} \\
& \varepsilon_{P M V, \text { cool }}=\frac{\sum_{k=0}^{N_{m}}\left|P M V_{i, k}-P M V_{\text {set }, k}\right|}{N_{\text {cool }}}
\end{aligned}
$$




$$
\varepsilon_{T_{o}}=\frac{\sum_{k=0}^{N_{N V}}\left|T_{o, k}-T_{N V_{-} s e t, k}\right|}{N_{N V}}
$$

652 Where $N_{\text {heat }}$ and $N_{\text {cool }}$ are the total number of hours where the mechanical heating/cooling 653 system mode was active (respectively in heating or cooling) and $N_{N V}$ is the total number of 654 hours where the system operated in natural ventilation mode. Each indicator acounted only the 655 instances when their respective operating mode was active Eq. 6 and Eq. 7 refer to Fanger’s 656 theory for a comfort Class B building, while Eq. 8 refers to the adaptive comfort band from 657 ASHRAE 55.

658 The amount of time the building was operating in free running mode is also presented in these 659 two tables (FR in Table 4 and Table 5), as a percentage of the total time (not a fraction of the 660 time in which the system was in the specific operating mode) the building was operating 661 without additional heating or cooling, i.e. when in natural ventilation mode, the controller 662 defined the windows position " $w p=0$ " as the optimal decision for ensuring adaptive thermal 663 comfort or when in mechanical conditioning mode, the controller selected an optimal PMV664 based set-point that is reachable without activating the heat-pump.

665 Table 4 reports the primary outcomes of the numerical simulations. The daily average energy 666 needed for the heating and cooling periods is also reported by assuming ideal systems. 
Table 4: Key performance indicators for the simulations.

\begin{tabular}{|c|c|c|c|c|c|c|c|c|c|}
\hline Month & Controller & $\begin{array}{l}\text { NV } \\
\text { (FR) [-] }\end{array}$ & $\begin{array}{l}\text { Heating } \\
\text { (FR) [-] }\end{array}$ & $\begin{array}{l}\text { Cooling } \\
\text { (FR) [-] }\end{array}$ & $\begin{array}{l}\varepsilon_{\text {To }} \\
{\left[{ }^{\circ} \mathrm{C} / \Delta \mathrm{t}\right]}\end{array}$ & $\begin{array}{l}\text { EPMV,heat } \\
{[-/ \Delta t]}\end{array}$ & $\begin{array}{l}\text { EPMV,cool } \\
{[-/ \Delta t]}\end{array}$ & $\begin{array}{l}\text { Heating } \\
\text { [kWh/day] }\end{array}$ & $\begin{array}{l}\text { Cooling } \\
\text { [kWh/day] }\end{array}$ \\
\hline & Baseline & $\begin{array}{l}78.1 \% \\
(0 \%)\end{array}$ & $\begin{array}{l}10.5 \% \\
(7.8 \%)\end{array}$ & $\begin{array}{l}11.3 \% \\
(0.2 \%)\end{array}$ & 1.508 & 0.608 & 0.731 & 0.385 & 5.726 \\
\hline Jan & Adaptive & $\begin{array}{l}88.7 \% \\
(42.7 \%)\end{array}$ & $\begin{array}{c}2.5 \% \\
(0.01 \%)\end{array}$ & $\begin{array}{c}8.7 \% \\
(1.2 \%)\end{array}$ & 1.101 & 0.077 & 0.064 & 1.260 & 1.748 \\
\hline & Baseline & $\begin{array}{c}37.5 \% \\
(0 \%)\end{array}$ & $\begin{array}{l}58.7 \% \\
(49.9 \%)\end{array}$ & $\begin{array}{l}3.7 \% \\
(0.1 \%)\end{array}$ & 1.318 & 0.273 & 0.327 & 0.652 & 1.171 \\
\hline Apr & Adaptive & $\begin{array}{l}90.0 \% \\
(67.6 \%)\end{array}$ & $\begin{array}{c}2.8 \% \\
(0.02 \%)\end{array}$ & $\begin{array}{l}7.0 \% \\
(3.6 \%)\end{array}$ & 1.053 & 0.076 & 0.065 & 0.905 & 0.797 \\
\hline & Baseline & $\begin{array}{l}3.3 \% \\
(0 \%)\end{array}$ & $\begin{array}{l}96.6 \% \\
(14.3 \%)\end{array}$ & $\begin{array}{l}0 \% \\
(0 \%)\end{array}$ & 1.054 & 0.142 & N/A & 12.734 & 0 \\
\hline Jul & Adaptive & $\begin{array}{l}51.2 \% \\
\text { (46.8\%) }\end{array}$ & $\begin{array}{l}48.7 \% \\
(1.8 \%)\end{array}$ & $\begin{array}{l}0 \% \\
(0 \%)\end{array}$ & 1.603 & 0.057 & N/A & 13.519 & 0 \\
\hline
\end{tabular}

669

670 Table 5 refers to the outcomes of the experimental tests. The tests were performed in a period

671 when mechanical cooling was not necessary. Outcomes carried out experimentally have the

672 limitations of comparing experimental tests undertaken at different time periods.

673 Table 5: Key performance indicators for the experimental tests.

\begin{tabular}{cccccc}
\hline Period & Controller & NV (FR) $[-]$ & Heating (FR) $[-]$ & $\varepsilon_{\mathrm{To}}\left[{ }^{\circ} \mathrm{C} / \Delta \mathrm{t}\right]$ & $\varepsilon \mathrm{PMV}$, heat $[-/ \Delta \mathrm{t}]$ \\
\hline 21-23 Apr & Baseline & $48.1 \%(0 \%)$ & $51.9 \%(39.6 \%)$ & 2.64 & 0.60 \\
26-29 May & Adaptive & $84.0 \%(71.9 \%)$ & $2.8 \%(0 \%)$ & 1.51 & 0.03 \\
30-31 May & Adaptive & $58.9 \%(58.4 \%)$ & $48.7 \%(0 \%)$ & 2.63 & 0.02 \\
\hline
\end{tabular}


675 The internal dead-bands of the air conditioning system baseline controller allowed the system 676 to heat the building $2{ }^{\circ} \mathrm{C}$ above the set-point. The resulting PMV was therefore always 677 significantly above -0.5 and even above 0 for a large fraction of the time. This effect was

678 limited by the comfort-oriented control strategy, which adjusted the heat pump set-point to 679 modulate the heating delivery and stopped the heat pump operation when the PMV reached a 680 level higher than the adaptive comfort requirements. When analysing the cumulative deviations 681 in Table 5, it can be seen that, during mechanical operation hours, the comfort-oriented control strategy performed better than the baseline. During the natural ventilation hours, the Adaptive

683 Comfort Controller in Test $1\left(26^{\text {th }}-29^{\text {th }}\right.$ May) outperformed the baseline Controller, since it 684 could utilise the outdoor conditions to properly maintain the indoor conditions close to the 685 required set-point. Optimising the mixing of outdoor air with the indoor to only occur when 686 favourable, and by controlling the exchange rate, made it possible to ensure the indoor 687 temperature was as close as possible to the set-point, with minimal oscillations around it.

688 During the second testing period $\left(30^{\text {th }}-31^{\text {st }}\right.$ May), the comfort-oriented control strategy had an 689 approximately similar performance to the baseline Controller. This is due to the very different 690 weather conditions during the two tests. In fact, during the second test, the windows were never 691 opened by the comfort-oriented control strategy, as the indoor air temperature was lower than the target temperature, but the outdoor temperature was always even lower than the indoor air 693 temperature.

\section{Conclusions}

695

The current paper proposed a comfort-oriented control strategy to manage a mixed-mode ventilation residential building. A residential building with operable windows, a reverse-cycle ducted air conditioner and comprehensive experimental control and monitoring infrastructure 
was used to experimentally and numerically test the performance of the proposed controller in comparison to a baseline one.

The proposed comfort-oriented control strategy acted on two control levels, where the higher level assessed the possibility to operate in natural ventilation mode based on the boundaries of the ASHRAE 55 adaptive thermal comfort model, and the lower level optimised the equipment operation depending on the chosen operating mode. If natural ventilation mode was selected from the higher level, the operation of the natural ventilation mode was optimised on the embedded controller, using the wind speed and direction measurements and the indoor and outdoor temperatures. A simplified airflow network of the building was solved in real time to predict the temperature of the air mix, to determine the window opening percentage that will more closely track the temperature target. If mechanical heating or cooling was selected, the optimal set-point of the air-conditioner was dynamically calculated by the controller, finding the indoor air temperature that would lead to the desired PMV level.

711 Benchmarking the performance of a controller is difficult via only experiments, as the results

712 are limited by the comparison of outcomes measured at different times. For this reason, a 713 building performance simulation model of the case-study building was developed using ESP-

714 r. The baseline and the comfort-oriented control strategy were coupled at time step level to the building simulation model. Numerical simulations proved the effectiveness of the comfortoriented control strategy in all seasons in terms of maintaining comfort in accordance with targets set by the current comfort standards, such as deviation from a PMV set-point or from

718 the middle of the adaptive thermal comfort band. The building energy consumption was also 719 reduced in cooling dominated conditions.

720 The comfort-oriented control strategy developed for this study was also experimentally compared with the standard baseline controller , and despite the limitations of comparing experimental tests that were undertaken at different time periods, it was shown that the comfort- 
723 oriented control strategy can outperform the baseline one, with the results being in accordance

724 to those from the simulations. When in natural ventilation mode, the comfort-oriented control

725 strategy better managed the opening of the windows, more closely tracking the middle of the

726 adaptive comfort band when compared to the baseline controller. Furthermore, in mechanical

727 conditioning mode, selecting the air temperature set-point with the control objective on the

728 target PMV allowed the comfort-oriented control strategy to deviate less from the desired PMV 729 level.

730 The present approach represents a reliable, affordable, and effective solution to deal with

731 mixed-mode buildings. Compared to alternative model-based approaches it requires a

732 significantly reduced fine-tuning effort enabling the present methodology to be easily

733 generalized to other buildings and climates.

734 Future work should focus on improving the controller performance using a multi-zone 735 regulation configuration instead of the existing single-zone, or alternative comfort models can be used to define the controller objectives. This could include including suing comfort metrics which are able to assess the users’ thermal comfort based on local phenomena (e.g. higher local air speeds), as well as include local discomfort drawbacks, such as the draught risk, in the controller's objectives.

\section{Acknowledgement}

742 The initial research in this paper was partly supported by the Australia-Germany Research

743 Cooperation Scheme, a joint initiative of Universities Australia and the German Academic

744 Exchange Service (DAAD). 
747

[1] D. Kolokotsa, D. Rovas, E. Kosmatopoulos, K. Kalaitzakis, A roadmap towards intelligent net zero- and positive-energy buildings, Sol. Energy. 85 (2011) 3067-3084. doi:10.1016/j.solener.2010.09.001.

[2] E. Mills, Building Commissioning: A Golden Opportunity for Reducing Energy Costs and Greenhouse Gas Emissions, 2009.

[3] G. Serale, M. Fiorentini, A. Capozzoli, D. Bernardini, Model Predictive Control ( MPC ) for enhancing buildings and HVAC systems energy efficiency : problem formulation , applications and opportunities, Energies. 11 (2018) 1-33.

[4] H.T. Haider, O.H. See, W. Elmenreich, A review of residential demand response of smart grid, Renew. Sustain. Energy Rev. 59 (2016) 166-178. doi:10.1016/j.rser.2016.01.016.

[5] D. Kolokotsa, K. Gobakis, S. Papantoniou, C. Georgatou, N. Kampelis, K. Kalaitzakis, K. Vasilakopoulou, M. Santamouris, Development of a web based energy management system for University Campuses: The CAMP-IT platform, Energy Build. 123 (2016) 119-135. doi:10.1016/J.ENBUILD.2016.04.038.

[6] R. Markovic, E. Grintal, D. Wölki, J. Frisch, C. Van Treeck, Window opening model using deep learning methods, Build. Environ. 145 (2018) 319-329. doi:10.1016/j.buildenv.2018.09.024.

[7] M. Santamouris, F. Allard, Natural ventilation in buildings: a design handbook, James and James (Science Publishers) Ltd, London, 1998.

[8] S. Drake, R. De Dear, A. Alessi, M. Deuble, S. Drake, R. De Dear, A. Alessi, M.D. Occupant, S. Drake, R. De Dear, A. Alessi, M. Deuble, Occupant comfort in naturally 
ventilated and mixed-mode spaces within air-conditioned offices, Archit. Sci. Rev. 53 (2010) 297-306. doi:10.3763/asre.2010.0021.

771

772

773

774

775

776

777

778

779

780

781

782

783

784

785

786

787

788

789

790

791

792

[9] K. Niachou, S. Hassid, M. Santamouris, I. Livada, Comparative monitoring of natural , hybrid and mechanical ventilation systems in urban canyons, Energy Build. 37 (2005) 503-513. doi:10.1016/j.enbuild.2004.09.016.

[10] X. Shao, X. Li, X. Ma, C. Liang, Multi-mode ventilation : An efficient ventilation strategy for changeable scenarios and energy saving, Build. Environ. 115 (2017) 332344. doi:10.1016/j.buildenv.2017.01.032.

[11] S. Manu, C. Patel, R. Rawal, G. Brager, Occupant feedback in air conditioned and mixed-mode office buildings in India, in: Proc. 9th Wind. Conf. Mak. Comf. Relev., n.d.: pp. 306-319.

[12] L.E. Thomas, Shifting the norm - towards effective mixed mode buildings, in: 30th Int. Plea Conf., Ahmedabab: pp. 1-8.

[13] J.C. Salcido, A. Abdul, R.R.A. Issa, From simulation to monitoring: Evaluating the potential of mixed-mode ventilation (MMV) systems for integrating natural ventilation in office buildings through a comprehensive literature review, Energy Build. 127 (2016) 1008-1018. doi:10.1016/j.enbuild.2016.06.054.

[14] Ventilative cooling through automated window opening control systems to address thermal discomfort risk during the summer period: Framework, simulation and parametric analysis, Energy Build. 153 (2017) 18-30.

doi:10.1016/J.ENBUILD.2017.07.088.

[15] M. Fiorentini, F. Tartarini, L. Ledo Gomis, D. Daly, P. Cooper, Development of an enthalpy-based index to assess climatic potential for ventilative cooling of buildings: An Australian example, Appl. Energy. (2019). doi:10.1016/j.apenergy.2019.04.165. 
793

794

795

796

797

798

799

800

801

802

803

804

805

806

807

808

809

810

811

812

813

814

815

[16] K. Huang, G. Feng, H. Li, S. Yu, Opening window issue of residential buildings in winter in north China: A case study in Shenyang, Energy Build. 84 (2014) 567-574. doi:10.1016/j.enbuild.2014.09.005.

[17] H.B. Rijal, P. Tuohy, M.A. Humphreys, J.F. Nicol, A. Samuel, J. Clarke, Using results from field surveys to predict the effect of open windows on thermal comfort and energy use in buildings, Energy Build. 39 (2007) 823-836. doi:10.1016/j.enbuild.2007.02.003.

[18] I.A. Raja, J.F. Nicol, K.J. Mccartney, M.A. Humphreys, Thermal comfort : use of controls in naturally ventilated buildings, Energy Build. 33 (2001) 235-244.

[19] T. Psomas, P. Heiselberg, T. Lyme, K. Duer, Automated roof window control system to address overheating on renovated houses : Summertime assessment and intercomparison, Energy Build. 138 (2017) 35-46. doi:10.1016/j.enbuild.2016.12.019.

[20] T. Psomas, P. Heiselberg, K. Duer, E. Bjørn, Overheating risk barriers to energy renovations of single family houses : Multicriteria analysis and assessment, Energy Build. 117 (2016) 138-148. doi:10.1016/j.enbuild.2016.02.031.

[21] S. Aggrholm, Perceived Barriers to Natural Ventilation Design of Office Buildings, 1998.

[22] M. Fiorentini, G. Kokogiannakis, W. Jackson, Z. Ma, Evaluation Methodology and Implementation for Natural Ventilation Control Strategies, Clima 2016 - RHEVA World Congr. Aalborg. (2016).

[23] R. Forgiarini, N. Giraldo, R. Lamberts, A review of human thermal comfort in the built environment, Energy Build. 105 (2015) 178-205. doi:10.1016/j.enbuild.2015.07.047.

[24] S. Carlucci, L. Pagliano, A review of indices for the long-term evaluation of the 
816

817

818

819

820

821

822

823

824

825

826

827

828

829

830

831

832

833

834

835

836

837

838

839

general thermal comfort conditions in buildings, Energy Build. 53 (2012) 194-205. doi:10.1016/j.enbuild.2012.06.015.

[25] S. Attia, S. Carlucci, Impact of different thermal comfort models on zero energy residential buildings in hot climate, Energy Build. 102 (2015) 117-128. doi:10.1016/j.enbuild.2015.05.017.

[26] D.H. Kang, P.H. Mo, D.H. Choi, S.Y. Song, M.S. Yeo, K.W. Kim, Effect of MRT variation on the energy consumption in a PMV-controlled office, Build. Environ. 45 (2010) 1914-1922. doi:10.1016/j.buildenv.2010.02.020.

[27] S.K. Gupta, S. Atkinson, I. O’Boyle, J. Drogo, K. Kar, S. Mishra, J.T. Wen, BEES: Real-time occupant feedback and environmental learning framework for collaborative thermal management in multi-zone, multi-occupant buildings, Energy Build. 125 (2016) 142-152. doi:10.1016/j.enbuild.2016.04.084.

[28] X. Fu, D. Wu, Comparison of the efficiency of building hybrid ventilation systems with different thermal comfort models, Energy Procedia. 78 (2015) 2820-2825. doi:10.1016/j.egypro.2015.11.640.

[29] P. May-Ostendorp, G.P. Henze, C.D. Corbin, B. Rajagopalan, C. Felsmann, Modelpredictive control of mixed-mode buildings with rule extraction, Build. Environ. 46 (2011) 428-437. doi:10.1016/j.buildenv.2010.08.004.

[30] J. Zhao, K. Poh, B.E. Ydstie, V. Loftness, Occupant-oriented mixed-mode EnergyPlus predictive control simulation, Energy Build. 117 (2016) 362-371. doi:10.1016/j.enbuild.2015.09.027.

[31] J. Hu, P. Karava, A state-space modeling approach and multi-level optimization algorithm for predictive control of multi-zone buildings with mixed-mode cooling, Build. Environ. 80 (2014) 259-273. doi:10.1016/j.buildenv.2014.05.003. 
840 [32] J. Hu, P. Karava, Model predictive control strategies for buildings with mixed-mode cooling, Build. Environ. 71 (2014) 233-244. doi:10.1016/j.buildenv.2013.09.005.

842

843

844

845

846

847

848

849

850

851

852

853

854

855

856

857

858

859

860

861

862

863

[33] H.C. Spindler, L.K. Norford, Naturally ventilated and mixed-mode buildings d Part II : Optimal control, Build. Environ. 44 (2009) 750-761.

doi:10.1016/j.buildenv.2008.05.018.

[34] H.C. Spindler, L.K. Norford, Naturally ventilated and mixed-mode buildings d Part I: Thermal modeling, Build. Environ. 44 (2009) 736-749. doi:10.1016/j.buildenv.2008.05.019.

[35] J. Chen, G. Augenbroe, X. Song, Lighted-weighted model predictive control for hybrid ventilation operation based on clusters of neural network models, Autom. Constr. 89 (2018) 250-265. doi:10.1016/j.autcon.2018.02.014.

[36] E. Barbadilla-martín, J. Guadix, J. Manuel, S. Lissén, J. Sánchez, S. Álvarez, Assessment of thermal comfort and energy savings in a field study on adaptive comfort with application for mixed mode offices, Energy Build. 167 (2018) 281-289. doi:10.1016/j.enbuild.2018.02.033.

[37] R. Forgiarini, R. De Dear, E. Ghisi, Field study of mixed-mode office buildings in Southern Brazil using an adaptive thermal comfort framework, Energy Build. 158 (2018) 1475-1486. doi:10.1016/j.enbuild.2017.11.047.

[38] G. Martín, E. Barbadilla-martín, P. Aparicio-ruiz, L. Brotas, Field study on adaptive thermal comfort in mixed mode office buildings in southwestern area of Spain Manuel Salmer o, Build. Environ. 123 (2017) 163-175. doi:10.1016/j.buildenv.2017.06.042.

[39] X. Deng, G. Kokogiannakis, Z. Ma, P. Cooper, Thermal comfort evaluation of a mixed-mode ventilated office building with advanced natural ventilation and underfloor air distribution systems, Energy Procedia. 111 (2017) 520-529. 

doi:10.1016/j.egypro.2017.03.214.

865

866

867

868

869

870

871

872

873

874

875

876

877

878

879

880

881

882

883

884

885

886

[40] R. De Vecchi, C. Candido, R. De Dear, R. Lamberts, Thermal comfort in office buildings : Findings from a field study in mixed-mode and fully-air conditioning environments under humid subtropical conditions, Build. Environ. 123 (2017) 672683. doi:10.1016/j.buildenv.2017.07.029.

[41] M. Lou, B. Cao, J. Damiens, L. Borong, Z. Yingxin, Evaluating thermal comfort in mixed-mode buildings : A field study in a subtropical climate, Build. Environ. 88 (2015) 46-54. doi:10.1016/j.buildenv.2014.06.019.

[42] A.C. Boerstra, J. Van Hoof, A.M. Van Weele, A new hybrid thermal comfort guideline for the Netherlands : background and development, Archit. Sci. Rev. 58 (2014) 24-34. doi:10.1080/00038628.2014.971702.

[43] ASHRAE, Standard 55 - Thermal environmental conditions for human occupancy, (2017).

[44] ASHRAE, 2017 ASHRAE Handbook - Fundamentals (SI Edition), American Society of Heating, Refrigerating and Air-Conditioning Engineers, Inc., 2017.

[45] ISO/TC159/SC5, ISO 7730:2005 - Ergonomics of the thermal environment -Analytical determination and interpretation of thermal comfort using calculation of the PMV and PPD indices and local thermal comfort criteria, (2005).

[46] B.W. Olesen, K.C. Parsons, Introduction to thermal comfort standards and to the proposed new version of EN ISO 7730, Energy Build. 34 (2002) 537-548. doi:10.1016/S0378-7788(02)00004-X.

[47] OASIS, oBIX, http://www.obix.org/ (accessed January 11, 2019).

[48] T. Psomas, M. Fiorentini, G. Kokogiannakis, P. Heiselberg, Ventilative cooling 

through automated window opening control systems to address thermal discomfort risk during the summer period: Framework, simulation and parametric analysis, Energy Build. 153 (2017). doi:10.1016/j.enbuild.2017.07.088.

[49] Lawrence Berkeley National Laboratories, Building Controls Virtual Test Bed (BCVTB). https://simulationresearch.lbl.gov/bcvtb (accessed June 25, 2019) 